Review

\title{
Hydrogen Gas Sensors Based on Semiconductor Oxide Nanostructures
}

\section{Haoshuang Gu *, Zhao Wang and Yongming Hu}

Faculty of Physics and Electronic Technology, Hubei University, Wuhan 430062, China;

E-Mails: wangzhaohubu@163.com (Z.W.); yongming.hu09@gmail.com (Y.H.)

* Author to whom correspondence should be addressed; E-Mail: guhsh583@yahoo.com.cn;

Tel.: +86-027-8866-5568; Fax: +86-027-8866-3390.

Received: 8 March 2012; in revised form: 1 April 2012 / Accepted: 25 April 2012 /

Published: 30 April 2012

\begin{abstract}
Recently, the hydrogen gas sensing properties of semiconductor oxide (SMO) nanostructures have been widely investigated. In this article, we provide a comprehensive review of the research progress in the last five years concerning hydrogen gas sensors based on SMO thin film and one-dimensional (1D) nanostructures. The hydrogen sensing mechanism of SMO nanostructures and some critical issues are discussed. Doping, noble metal-decoration, heterojunctions and size reduction have been investigated and proved to be effective methods for improving the sensing performance of SMO thin films and 1D nanostructures. The effect on the hydrogen response of SMO thin films and 1D nanostructures of grain boundary and crystal orientation, as well as the sensor architecture, including electrode size and nanojunctions have also been studied. Finally, we also discuss some challenges for the future applications of SMO nanostructured hydrogen sensors.
\end{abstract}

Keywords: hydrogen gas sensor; semiconductor oxides; nanostructure; thin films; one-dimensional nanostructures

\section{Introduction}

Hydrogen is regarded as one of the best clean energy carriers, which is the ultimate fossil fuel candidate, with a high heat of combustion $(142 \mathrm{~kJ} / \mathrm{g})$, low minimum ignition energy $(0.017 \mathrm{~mJ})$ and wide flammable range (4-75\%), as well as high burning velocity. The combustion product of hydrogen is water, which is free from contamination and can be converted into hydrogen and oxygen again for 
periodic duty. Liquid hydrogen has already been used for rocket fuels. Moreover, hydrogen is also used in metal smelting, glassmaking, semiconductor processing, petroleum extraction and the daily chemical industry, etc. due to its strong reducing properties. In addition, hydrogen can also be applied in biomedical, environmental protection and seismic surveillance area such as for indicating certain type of bacterial infection, detection of environmental pollution, etc.

Hydrogen gas is tasteless, colorless and odorless so it cannot be detected by human beings. The low ignition energy and wide flammable range makes it easy inflammable and explosive. Therefore rapid and accurate hydrogen detection is necessary during the production, storage and use of hydrogen and it is also essential for monitoring/controlling the hydrogen concentration of nuclear reactors, coal mines and semiconductor manufacturing, etc. [1-3].

As the traditional hydrogen detectors such as gas chromatographs, mass spectrometers and specific ionization gas pressure sensors are limited by their large size, expensive cost and slow response and sometimes high temperature of use, with potential safety hazards, hydrogen gas sensors of smaller size, lower production cost and power consumption, as well as lower operation temperature and faster response are required for widespread use such as portable and in-situ monitoring, and the rapid development of the hydrogen economy has promoted research on new types of hydrogen gas sensors with more rapid and accurate hydrogen sensing, near room temperature (RT) operation without power sources and compatibility with microelectronic integrated circuits.

As present, there are many types of the commercially available hydrogen sensors, including electrochemical, semiconductor, thermoelectric, metallic, optical and acoustic ones, etc. Among them, semiconductor sensors exhibit high sensitivity, fast response, long-term stability and potential for integration in hydrogen sensing performance [4-7]. Figure 1 shows the growing number of relevant publications about semiconductor hydrogen sensors. This type of hydrogen sensors still suffers however from high operation temperatures, which results in high power consumption and potential safety hazards. Moreover, the cross selectivity to other combustible or reducing gases is another critical issue, which should be restricted to enhance the sensing accuracy.

Figure 1. Publications about semiconductor hydrogen sensors since 1996 according to an enquiry in Thomson Reuters ISI Web of Knowledge.

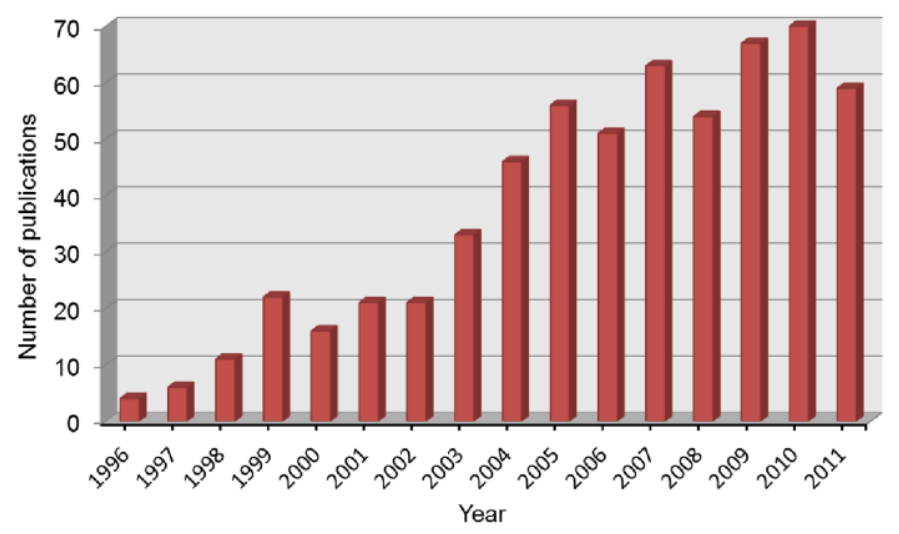

In recent years, semiconductor nanostructures such as nanowires (NWs) and thin films have been employed as sensing materials for building high-performance hydrogen sensors due to their high specific surface area and novel electron transportation properties. For instance, mesoporous thin films 
or nanotube arrays synthesized by anodic oxidization shows enhanced hydrogen sensing properties compared to traditional film-based sensors due to the greater specific surface area [8-14]. As for the dimensional reduction, 1D nanostructures show much higher sensing performance such as higher sensitivity, broader limit of detection (LOD), lower operation temperature and response time than thin films [15,16]. In addition, nanoparticles-decoration semiconductor nanostructures have also been widely investigated for increasing of sensitivity and selectivity to hydrogen gas $[17,18]$.

In this review, the recent research efforts made in gas sensors based on semiconductor oxide (SMO) nanostructures are comprehensively reviewed. Among them, the research works on thin film and 1D nanostructures reviewed in this article are mainly published in the past five years. In Section 2, the sensing mechanism of hydrogen sensors based on metal oxide semiconductor nanostructures and their critical issues will be introduced. In Section 3, the recent research progress of hydrogen sensors based on SMO thin film and 1D nanostructures will be reviewed, respectively.

\section{Classification and Critical Issues of SMO Hydrogen Sensors}

\subsection{Types of SMO Hydrogen Sensors}

As a hydrogen detecting device, the hydrogen sensor is essentially a transducer that transforms the variation of physical or chemical properties into an electrical signal for practical applications. According to the variation of electrical and optical properties of SMOs under a hydrogen-containing atmosphere, the SMO hydrogen sensors can be divided into four types: resistance based, work function based, optical and acoustic sensors.

\subsubsection{Resistance-Based}

In 1950, Wagner et al. reported the variation of electrical properties when $\mathrm{ZnO}$ is exposed to reducing gases [19]. After that, a series of research works about the sensing behavior of SMO to reducing gases were reported by Seiyama, et al. since the 1960s [20]. Up to present, many kinds of SMO were investigated as hydrogen sensing materials, including $\mathrm{SnO}_{2}, \mathrm{ZnO}, \mathrm{TiO}_{2}, \mathrm{Nb}_{2} \mathrm{O}_{5}, \mathrm{In}_{2} \mathrm{O}_{3}, \mathrm{FeO}$, $\mathrm{Fe}_{2} \mathrm{O}_{3}, \mathrm{NiO}, \mathrm{Ga}_{2} \mathrm{O}_{3}, \mathrm{Sb}_{2} \mathrm{O}_{5}, \mathrm{MoO}_{3}, \mathrm{~V}_{2} \mathrm{O}_{5}$ and $\mathrm{WO}_{3}$, which exhibit large variations in resistance after exposure to hydrogen gas. Among them, $\mathrm{SnO}_{2}$ and $\mathrm{ZnO}$ are the mostly used SMOs in the resistance type hydrogen sensors. For instance, several studies have been carried out on the hydrogen sensing properties of $\mathrm{SnO}_{2}$ and $\mathrm{ZnO} 1 \mathrm{D}$ nanostructures as resistance type sensors since the first report on the gas sensing performance of $\mathrm{SnO}_{2}$ nanobelts [21,22].

Figure 2 shows the typical structure of a resistance based SMO hydrogen sensor, which consists of a SMO layer on an insulating substrate and two electrodes, as well as a heater under the sensitive layer. During operation the sensitive layer will be heated to a certain temperature for enhancement of the sensing performance. This temperature, which depends on the sensitive oxide materials used, is typically several hundred degrees Celsius. The resistance $(R)$ of the sensitive layer will change due to the exposure to hydrogen gas. The variation depends on the hydrogen concentration and exhibits an approximately linear relationship with the hydrogen concentration within a certain range. 
Figure 2. Schematic of a resistance based SMO hydrogen sensor.

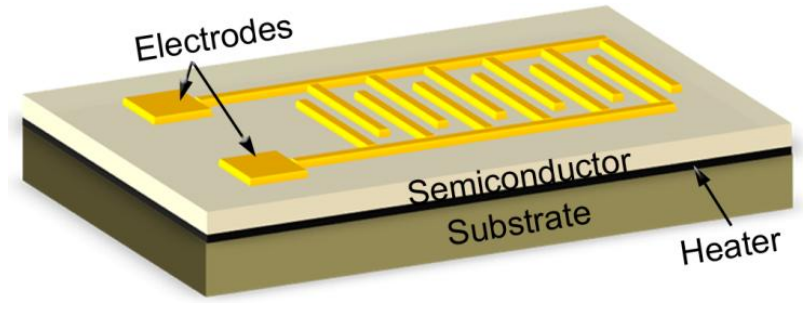

The resistance-based sensing mechanism of SMO is complicated, and has been investigated by many researchers. The commonly accepted mechanism is based on the variation of the surface electron depletion region due to the reaction between hydrogen and the chemisorbed oxygen on the surface. As described in Figure 3, under an air atmosphere the oxygen molecules can get adsorbed on the surface of the semiconductor and extracts electrons from the conduction band to form oxygen ions. That may lead to the formation of an electron depletion region near the surface, which can greatly increase the resistance due to the decrease of net carrier density. When the sensor is exposed to a hydrogen atmosphere, the hydrogen molecules will react with the adsorbed oxygen species. The redox reaction is exothermic and results in the fast desorption of produced $\mathrm{H}_{2} \mathrm{O}$ molecules from the surface. The released electrons will reduce the thickness of the depletion region, and decrease the resistance of the semiconductors. When the sensor is exposed to the air ambient again, the depletion region will be rebuilt by adsorbed oxygen species. The resistance will regain the initial level before hydrogen response.

Figure 3. The hydrogen sensing mechanism of resistance based SMO sensors.

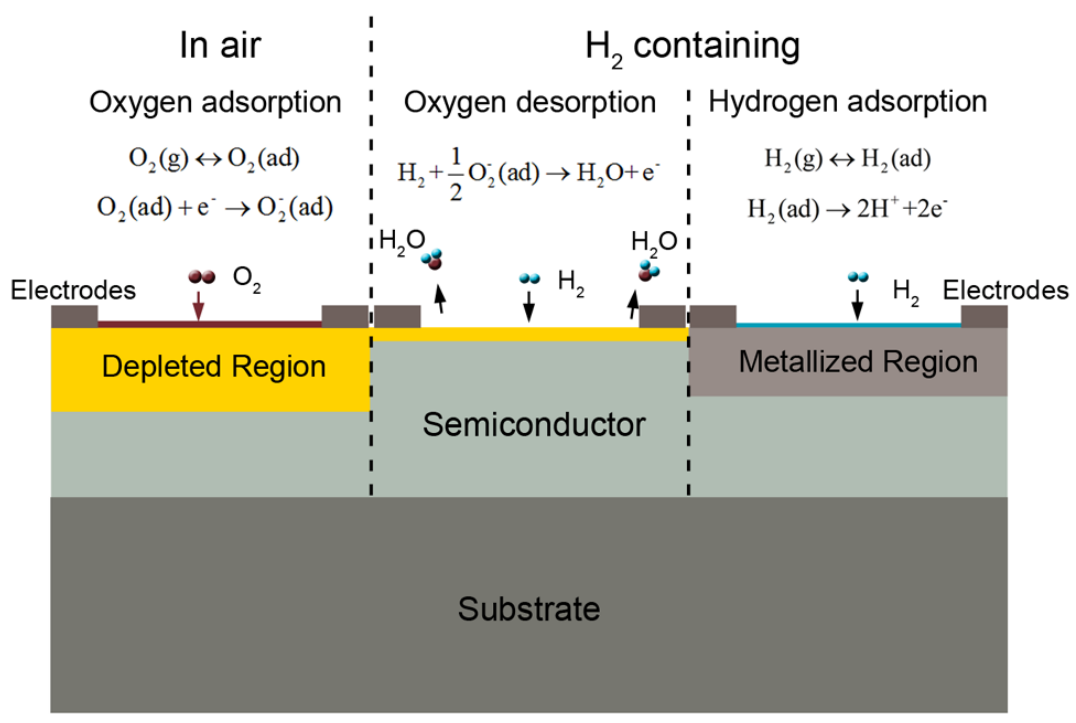

Moreover, the surface chemisorption of dissociated hydrogen may also play an important role in the hydrogen sensing behavior. As reported, hydrogen dissociated on the surface of a semiconductor induces an intermediate energy level for the transfer of charges from hydrogen to the conduction band. An accumulation layer of electrons is therefore created and results in a metalized region near the surface, which may greatly decrease the semiconductor resistance. When the hydrogen ambient was removed by air, the accumulation layer of electrons would be eliminated, and this leads to the recovery of resistance. Wang et al. have studied the hydrogen-induced metallization of $\mathrm{ZnO}$ and found that the 
$\mathrm{ZnO}$ surfaces and NWs became metallic when surface oxygen $(\mathrm{O})$ atoms were saturated by hydrogen [23]. $\mathrm{Xu}$ et al. have also demonstrated a first-principles study of hydrogen adsorption on $\mathrm{ZnO} \mathrm{NWs}$ and found that the adsorption with half a monolayer of hydrogen on an oxygen surface induces metallic behavior [24]. This process has also been reported for $\mathrm{TiO}_{2}$ based hydrogen sensors [25,26].

\subsubsection{Work Function-Based}

This type of hydrogen sensors are operated based on the variation of work function induced by hydrogen. The work function based sensors is generally formed by the metal/oxide/semiconductor (MOS) layers. According to the difference in structure, the work function based hydrogen sensors can be divided into three major types: the Schottky diode type, MOS capacitor type and the MOS field effect transistor (MOSFET) type.

\section{(1) Schottky Diode}

As shown in Figure 4(a), a Schottky diode type hydrogen sensor consists of a metal-(oxide)semiconductor-metal structure. The top electrode is the gas sensitive metal layer, which forms a Schottky contact at the interface between the metal and semiconductor (or a thin oxide layer deposited on the semiconductor), while the bottom electrode is a metal layer that form Ohmic contact with the semiconductor film, or sometimes a gas sensitive metal layer as well to form the back-to-back Schottky junction structure (mostly used for semiconductor thin film or NW based hydrogen sensors).

Figure 4. The schematic diagram of work function based SMO hydrogen sensors.

(a) Schottky diode type; (b) MOS capacitor type; (c) MOSFET type.

(a)

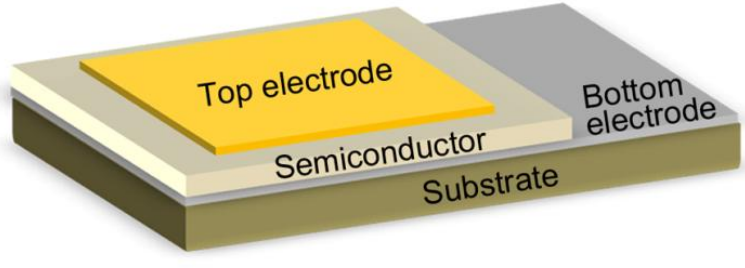

(b)

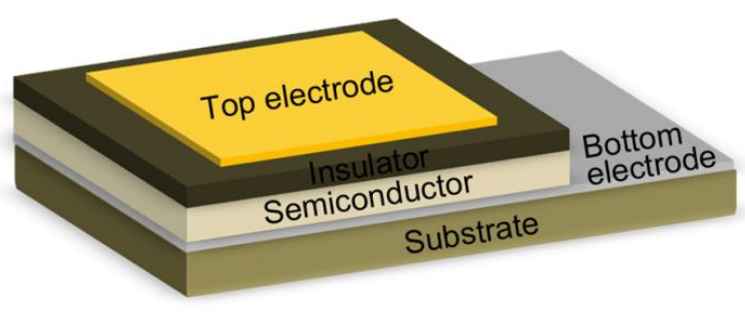

(c)

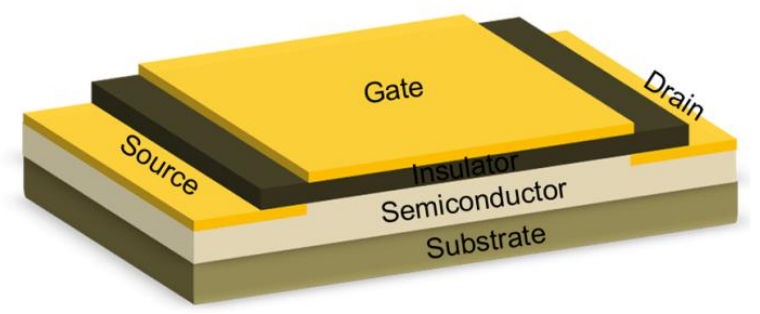

Hydrogen molecules can get adsorbed and dissociated into hydrogen atoms in the gas sensitive metal layer (generally $\mathrm{Pd}, \mathrm{Pt}, \mathrm{Au}, \mathrm{Ag}$ and $\mathrm{Cu}$, etc.). The diffusion of hydrogen atoms may lead to the 
formation of dipole layer at the interface between metal and oxide, which changes the work function of the metal and results in the variation of Schottky barrier height at the interface. Consequently, the measured voltage in $I-V$ curve will be shifted corresponding to the adsorbed hydrogen atoms, which can be used for detecting concentrations. An alternative explanation of the sensing mechanism was carried out by Yamamoto et al. by employing a $\mathrm{Pd} / \mathrm{TiO}_{2}$ Schottky diode sensor [27]. They suggested that the decrease of work function of $\mathrm{Pd}$ should be attributed to the reaction of adsorbed oxygen anions on Pd with the hydrogen species. Moreover, Zemel and co-workers attributed that to the hydrogen induced interface states that resulted in the change in electrical properties [28].

Several SMOs were employed to form the Schottky diode sensors, including $\mathrm{SnO}_{2}, \mathrm{TiO}_{2}, \mathrm{ZnO}$ and $\mathrm{Nb}_{2} \mathrm{O}_{5}$, etc. For instance, Lu et al. have reported a Schottky diode type hydrogen sensor based on nanostructured $\mathrm{SnO}_{2}$ films with $\mathrm{Pd}$ electrodes [29]. The sensor exhibited high sensitivity and fast response (less than $10 \mathrm{~s}$ ) to $100 \mathrm{ppm}$ of hydrogen gas at $300{ }^{\circ} \mathrm{C}$ under a forward bias voltage of $0.5 \mathrm{~V}$. Hyodo, Shimizu, Iwanaga and Miyazaki, et al. have demonstrated a series of research works about the $\mathrm{Pd} / \mathrm{TiO}_{2}$ Schottky diodes hydrogen sensor based on nanoporous $\mathrm{TiO}_{2}$ films $[8,9,13,30]$. They suggested that higher sensitivity could be obtained under reverse bias conditions than with forward biased conditions. A high performance Schottky diode type hydrogen sensor was reported by Das et al., which is fabricated based on individual $\mathrm{ZnO} \mathrm{NW}$ and Pt electrodes and exhibited sensitive and fast response at RT [31]. Similar research works have also been reported by Kim and Shafiei et al. [32,33]. Moreover, Hyodo et al. also reported a diode type $\mathrm{Pd} / \mathrm{Nb}_{2} \mathrm{O}_{5}$ hydrogen sensor based on nanoporous $\mathrm{Nb}_{2} \mathrm{O}_{5}$ films [14].

SMOs were also used to fabricate SiC-based Schottky diode hydrogen sensors. For example, Yu, Kandasamyu, Shafiei, Wlodarski and co-workers have reported several hydrogen sensors based on this structure, including $\mathrm{Pt} / \mathrm{ZnO}$-nanorod (NR)/SiC, $\mathrm{Pt} / \mathrm{TiO}_{2} / \mathrm{SiC}$ and $\mathrm{Pt} / \mathrm{SnO}_{2}-\mathrm{NWs} / \mathrm{SiC}$ Schottky diodes [34-37]. These sensors exhibited wide range of operation temperature and obvious work function shifts under forward and reverse biased conditions.

In addition, ferroelectric oxides were also employed as the oxide layer for fabricating hydrogen sensors with catalytic-metal/ferroelectric/metal structures. Although this type of ferroelectric device is always used as a capacitor and was categorized as a capacitor type hydrogen sensor by Hübert et al., their catalytic-metal/ferroelectric/metal structure resemble more closely the diode type [1]. Zhu, Tan and co-workers have demonstrated several ferroelectric thin film capacitor hydrogen sensors since 1998, including $(\mathrm{Ba}, \mathrm{Sr}) \mathrm{TiO}_{3}$ and $\mathrm{Pb}(\mathrm{Zr}, \mathrm{Ti}) \mathrm{O}_{3}$ ones [38-40]. All these ferroelectric-based hydrogen sensors show shifted $I-V$ curves under a hydrogen-containing atmosphere. They attributed it to the lowering of Schottky barrier height through charges induced by hydrogen ions at the interface. Moreover, they suggested that the high permittivity of the amorphous ferroelectric thin films can enhance the proton polarization at the metal/ferroelectric interface and greatly improves the built-up interfacial potential induced by the hydrogen. A detailed review was also carried out by them in 2003 [41]. Besides, Nakagomi also reported a hydrogen sensor based on a $\mathrm{K}_{1-\mathrm{x}} \mathrm{Na}_{\mathrm{x}} \mathrm{NbO}_{3}$ thin film in 2005 [42].

(2) MOS Capacitor

As shown in Figure 4(b), the MOS capacitor hydrogen sensors are similar in structure to the above mentioned Schottky diode type sensors. However, a thick insulator layer is deposited between the 
catalytic sensitive metal layer and the semiconductor layer to prevent the current conduction and build up a charge-accumulation layer on both sides. When the sensor is exposed to a hydrogen-containing atmosphere, the dissociated hydrogen atoms can diffuse into the metal/insulator interface and lead to a lateral shift in the $C-V$ and $G-C$ plots corresponding to the hydrogen concentration.

Steele et al. firstly reported the MOS capacitor type of hydrogen sensors in 1976 [43]. After that, a series of research works have discussed silicon-based capacitor hydrogen sensors. In recent years, most of the reported MOS capacitor hydrogen sensors were based on a $\mathrm{SiO}_{2}$ insulator with a layer of palladium on top. However, several investigations on MOS capacitor hydrogen sensors based on SMOs were also carried out. For instance, Kang et al. have developed a class of MOS capacitor gas sensors in 1994, which employed $\mathrm{SnO}_{\mathrm{x}}$ and $\mathrm{ZnO}$ as the gas-adsorptive oxide layer on silicon [44]. The sensor shows enhanced hydrogen sensing properties at low temperature. They attributed it to the hydrogen dipoles in addition to the reduction of chemisorbed oxygen at the interface. Dwivedi and co-workers have investigated the effect of hydrogen-induced interface traps on a titanium dioxide-based palladium gate MOS capacitor [45]. The device is sensitive to hydrogen (1-3\%) at RT, where the interface state density $\left(D_{\mathrm{it}}\right)$ increases with the hydrogen gas concentration.

Recently, Yadav and co-workers have demonstrated a $\mathrm{Pd} / \mathrm{TiO}_{2} / \mathrm{Si} \mathrm{MOS}$ hydrogen sensor, which exhibited larger lateral shift in $C-V$ and $G-V$ response and short response time ( $<30 \mathrm{~s})$ with exposure to $4 \%$ of hydrogen gas in nitrogen at RT [46]. Weng and co-workers have reported a $\mathrm{Pd} / \mathrm{TiO}_{2} / \mathrm{SiO}_{2} / \mathrm{SiC}$ capacitor gas sensor working at high temperature [47]. They explained the leakage current detecting mechanism by a trap-assisted conduction model that the barrier height can be changed corresponding to the hydrogen concentration.

\section{(3) MOSFET}

Figure 4(c) shows the schematic diagram of a MOSFET or metal-insulator-semiconductor field effect transistor (MISFET) hydrogen sensor, which is also based on the variation of work function of the catalytic hydrogen sensitive metal (gate electrode) under exposure to hydrogen gas. Typically, the MOSFET device consists of a metal-SiO $2-\mathrm{Si}$ structure, in which two $\mathrm{Si}$ regions were ion-implanted to form the source and drain. Moreover, the Schottky barrier between metal and semiconductor can also be used for building the source and drain junction, especially when the MOSFET is formed based on the 1D nanostructures. After the source is grounded, the conductivity between source and drain can be modified by adjusting the gate voltage $\left(V_{\mathrm{GS}}\right)$. When this sensor is exposed to a hydrogen-containing atmosphere, the hydrogen atoms diffused to the interface between metal and insulator can form a dipole layer and thus change the gate voltage, which finally results in the variation of measured voltage signal corresponding to the hydrogen concentration.

Lundström and Stilbert, et al. first reported the MOSFET type hydrogen sensor in 1975 [48,49]. Recently, several research works about MOSFET gas sensors based on SMOs were published, while only a few research works about hydrogen sensors have been reported. For instance, Zeng et al. demonstrated a $\mathrm{H}_{2} \mathrm{~S}$ sensor based on a single $\mathrm{In}_{2} \mathrm{O}_{3} \mathrm{NW}$ transistor [50]. Zhang et al. reported an $\operatorname{In}_{2} \mathrm{O}_{3}$ NW FET gas sensor with high performance towards $\mathrm{NH}_{3}$ [51]. Anderi and co-workers reported a FET device based on an individual $\mathrm{SnO}_{2}$ nanobelt, which was modeled as two back-to-back Schottky diodes with a series resistance from the $\mathrm{SnO}_{2}$ nanobelt [52]. They suggested that the sensor worked as a FET 
only when it was exposed to hydrogen-containing condition, where the rectifying behavior of the source and drain contacts disappear, and the resistance of the device could be modulated by the gate voltage.

\subsubsection{Optical SMO Sensor}

Optical SMO hydrogen sensors are based on the variation of optical properties of SMO materials or the whole sensor when they are exposed to a hydrogen-containing environment. Most optical hydrogen sensors are based on thin films coated onto the tip or side wall of an optical fiber. These optical fiber based hydrogen sensors are always known as optrodes or optodes [53].

Typically, SMO optical hydrogen sensors operate based on the measurement of the evanescent field interaction. The evanescent field is always formed at the boundary between certain different media such as the core of an optical fiber. Evanescent field decays exponentially with the distance from the optical fiber. SMO thin films can be deposited onto a polished optical fiber as a sensing layer. The refractive index of the SMO layer will be changed by the exposure to hydrogen, and result in an attenuation change in the evanescent field, which can be detected as a change in transmittance. Sekimoto and co-workers reported a $\mathrm{WO}_{3}$ based evanescent wave hydrogen sensor with $\mathrm{Pd}$ and $\mathrm{Pt}$ catalyst in 2000 [54]. The refractive index of $\mathrm{WO}_{3}$ changed during its reaction with hydrogen, which is coupled to the evanescent field, and results in the variation of the power intensity of fiber with the hydrogen concentration.

\subsubsection{Acoustic Sensors}

Acoustic hydrogen sensors operate basing on the variation of acoustic wave properties (e.g., resonance frequency) of the piezoelectric materials due to adsorption of hydrogen onto the sensing layers. As known, the resonance frequency of bulk and surface acoustic wave (BAW, SAW) devices is sensitive to the accumulation of mass on the surface of the piezoelectric materials, which is always used to measure the mass of concentration of loading matters in ambient or in liquid conditions and possess ultra-high sensitivity.

Figure 5. The schematic diagram of a SAW hydrogen sensor.

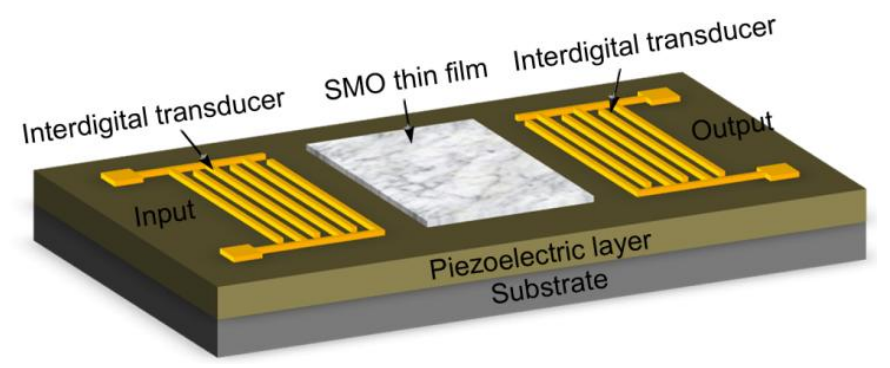

Figure 5 shows a typical structure of a SAW hydrogen sensor. Two interdigitated transducers (IDTs) were deposited on a piezoelectric film. The input IDT converts the applied electrical signal into acoustic waves by the inverse piezoelectric effect. The generated acoustic waves propagate along the surface within 1 or 2 acoustic wavelengths, and are converted back to electrical signals by the output IDT. The acoustic wave is very sensitive to the variation of surface conditions, and therefore can be 
used in hydrogen sensing when a SMO thin film hydrogen sensing layer is deposited on the surface of the piezoelectric layer between the IDTs. The hydrogen concentration can be detected by the frequency shift tested on the output port of the SAW device. The piezoelectric materials mostly employed for fabricating acoustic wave devices were $\mathrm{LiNbO}_{3}, \mathrm{LiTaO}_{3}$ and $\mathrm{AlN}$, etc., while $\mathrm{WO}_{3}, \mathrm{ZnO}$ and $\mathrm{InO}_{\mathrm{x}}$ were often used as SMO sensing layer [55-58].

\subsection{Critical Issues}

Among the reported investigations about SMO-based hydrogen sensors, the sensitivity, response, recovery time, gas selectivity, LOD and the temperature stability were always of concern, while the humidity and long-term stability were seldom investigated.

The sensitivity of resistance type hydrogen sensors can be defined as $S=R_{0} / R_{\mathrm{g}}$ for $n$-type SMOs and $S=R_{\mathrm{g}} / R_{0}$ for $p$-type SMOs, while some are defined as the relative change of the resistance $S=\Delta R / R_{0}$ or $S=\Delta R / R_{\mathrm{g}}$, where $R_{0}$ and $R_{\mathrm{g}}$ are the resistance measured before and after exposure to hydrogen, respectively. The response and recovery time is always defined as the time needed for the device to undergo a $90 \%$ change in the sensitivity in equilibrium upon exposure to hydrogen gas. According to the definition of LOD, it should be the lowest concentration that can be detected with three-times higher than the background signal. Therefore, LOD should be estimated by extrapolating the concentration dependent $S$ to $3 \sigma / R_{0}$, where $\sigma$ is the standard deviation of $R_{0}$. However, most investigations reported their LOD by directly pointing out the measured concentrations in their experiments, while some do not mention the LOD of their hydrogen sensors. Therefore, we only listed the experimentally measured range of hydrogen concentration in the literatures. Moreover, hydrogen sensors must pick out and measure the hydrogen gas from a complicated ambient in the environment to meet the demands for different applications. However, most of SMOs are sensitive to other reducing gas besides $\mathrm{H}_{2}$, such as $\mathrm{CO}, \mathrm{H}_{2} \mathrm{~S}, \mathrm{C}_{2} \mathrm{HOH}$ and $\mathrm{CH}_{4}$, etc. Therefore, the improvement of hydrogen gas selectivity is crucial in the R\&D of SMO hydrogen sensors. Size reduction, surface modification by nanoparticles and doping are efficient methods for increasing the hydrogen gas selectivity of SMOs.

Temperature is an important factor that greatly influences the hydrogen response of SMO sensors. Usually, higher temperature would lead to higher sensing performance due to the lowering of activation energy for gas adsorption and desorption. However, the sensitivity reached a best value and then decreased with the increasing temperature in some reports [59,60]. This phenomenon was explained as the disappearance of the depletion layers at the grain boundaries under high temperature. In addition, a major object in the research of SMO hydrogen sensors is to decrease the operation temperature (even to RT) with considering the reduced power consumption and elimination of safety problems. However, the temperature stability should be taken into account, especially for the RT sensors. Maybe a little higher temperature $\left(<100^{\circ} \mathrm{C}\right)$ would be better to render the required stability.

Humidity of the environment has also been taken into account by researchers as an important factor to the hydrogen sensing of SMOs. As reported by Zhang and Gong, et al., water absorbing on the surface of SMOs will lower the sensitivity of gas sensors [61,62]. Firstly, the reaction between the surface oxygen and the water molecules leads to a decrease in baseline resistance of the gas sensor, and results in a decrease of the sensitivity. Secondly, water molecules adsorbed on the surface lead to lower surface absorption site for chemisorption of oxygen species, which results in lower sensitivity. 
Besides, high humidity may also result in poor repeatability of the sensing performance. Therefore, the influence of humidity should be restrained or eliminated either by the design of material and device structure or by inducing the humidity compensation to the sensitivity.

The long-term stability is a key factor for gas sensors, but it is always been ignored by researchers, which has limited the practical applications of the sensors, especially when the sensors are operating at elevated temperatures. The grain size, necks and boundaries as well as the surface defects would be changed during the long-term operation at high temperatures, which leads to the variation of hydrogen response under the same condition and decreases the sensor stability [16]. Therefore, nanostructures with single crystalline structure such as single crystalline NWs possess better long-term stabilities than polycrystalline nanostructures, especially when the sensor is based on individual single crystalline NWs with no nanojunctions. The better long-term stability of NW-based gas sensors has already been found for other kinds of gas sensors, such as the randomly oriented single crystal $\mathrm{SnO}_{2} \mathrm{NWs}$ invested by Sysoev and co-workers [63], and the individual NW-based sensors demonstrated by Hernadez-Ramirez et al. [64].

\section{Hydrogen Sensors Based on SMO Thin Films and 1D Nanostructures}

\subsection{Thin Films}

Nanocrystalline thin films, which are two-dimensional nanostructures, have already been investigated as gas sensing materials for many years. Recently, SMO thin films have attracted considerable interest as hydrogen sensing materials due to their higher specific surface area and smaller grain size than bulk materials, which can lead to higher response, lower operating temperatures and fast response processes. Moreover, along with the development of synthesis techniques, hydrogen sensors based on SMOs thin films exhibit good compatibility with integrated circuits for building integrated sensors. In recent years, a lot of factors have been investigated for improving the sensing performance of thin film hydrogen sensors, e.g., particle size, porosity, orientation, doping effect, noble metal compositing and electrode architecture, etc. In this section, the review of studies on hydrogen sensing of SMO thin film are mainly focused on the reports during the last five years. Among numerous $\mathrm{SMOs}, \mathrm{SnO}_{2}, \mathrm{TiO}_{2}$ and $\mathrm{ZnO}$ thin films were mostly investigated, while $\mathrm{In}_{2} \mathrm{O}_{3}, \mathrm{WO}_{3}$, $\mathrm{CuO}$, and $\mathrm{NiO}$ thin films were also employed as hydrogen sensing materials.

Most of the SMO thin film hydrogen sensors are resistance type ones, which operate based on the variation of conductivity of the SMOs. Table 1 lists the recent studies on the hydrogen sensing performance of the resistance based SMOs. We have made a suitable transformation to these data, especially the sensitivity which were uniformed to be $S=R_{0} / R_{\mathrm{g}}$. Thus, the sensor responses from other literature in Table 1 are comparable. For instance, Adamyan and co-workers have reported the hydrogen sensing performance of the nanocrystalline $\mathrm{SnO}_{2}$ thin films with high sensitivity derived from a sol-gel annealing process, which is a common method for fabricating nanocrystalline oxide thin films and ensures the high-temperature stability of the nanocrystalline grains $[65,66]$. They suggested that pulse heating treatment during the sensing process could reduce the influence of environmental humidity, improve the stability and reduce the performance drift. As shown in Figure 6, they also studied the sensor parameters in real time during short- and long-term operation, which is always 
ignored by researchers. The sensing parameters were improved by a long-term treatment with an increase of sensitivity on more than two orders of magnitude. They attributed the improvement of performance to the diminished oxygen adsorption on defects during subsequent sensor operation in a hydrogen atmosphere. The diminishing oxygen adsorption on defects can reduce the local fields of defects and increase the oxygen adsorption on regular lattice atoms of the surface, which can enhance the hydrogen response. This work has had a great impact on emphasizing the importance of long-term stability of SMOs nanostructure-based hydrogen sensors.

Table 1. The recent developed SMO thin film based resistance hydrogen sensors.

\begin{tabular}{|c|c|c|c|c|c|c|c|c|}
\hline \multirow[b]{2}{*}{ Materials } & \multirow[b]{2}{*}{$\begin{array}{l}\text { Synthesis } \\
\text { Method }\end{array}$} & \multirow[b]{2}{*}{$\begin{array}{c}\text { Working } \\
\text { Temp. }\left({ }^{\circ} \mathrm{C}\right)\end{array}$} & \multirow[b]{2}{*}{$\begin{array}{c}\text { Detected } \\
\text { Conc. (ppm) }\end{array}$} & \multicolumn{4}{|c|}{ Hydrogen response } & \multirow[b]{2}{*}{ Ref. } \\
\hline & & & & $S_{\max }$ & $\begin{array}{l}\text { Conc. } \\
\text { (ppm) }\end{array}$ & $\mathbf{t}_{\text {response }}$ & $\begin{array}{l}\text { Temp. } \\
\left({ }^{\circ} \mathbf{C}\right)\end{array}$ & \\
\hline $\mathrm{SnO}_{2}$ & Sol-gel annealing & $100-300$ & $50-5,000$ & $10^{4}$ & 5,000 & $<10 \mathrm{~s}$ & 100 & {$[65]$} \\
\hline $\begin{array}{l}\mathrm{In}_{2} \mathrm{O}_{3} \text { doped } \\
\mathrm{SnO}_{2}\end{array}$ & Sol-gel annealing & 22 & $100-15,000$ & $10^{5}$ & 15,000 & tens of min. & 22 & {$[83]$} \\
\hline$(101)-\mathrm{SnO}_{2}$ & $\begin{array}{l}\text { RF magnetron } \\
\text { sputtering }\end{array}$ & 550 & $300-10,000$ & 300 & 10,000 & $<16 \mathrm{~s}$ & 550 & {$[70]$} \\
\hline $\begin{array}{l}\text { SWCNT } \\
\text { doped } \mathrm{SnO}_{2}\end{array}$ & Sol-gel annealing & $150-300$ & $300-1,500$ & 3 & 1,500 & $<5 \mathrm{~s}$ & 250 & {$[80]$} \\
\hline $\begin{array}{l}\mathrm{Au} \text { or } \mathrm{Pt} \\
\text { enhanced } \\
\mathrm{SnO}_{2}\end{array}$ & Sol-gel annealing & 85-180 & $500-10,000$ & 2 & 10,000 & several min. & 150 & {$[79]$} \\
\hline $\mathrm{SnO}_{2}$ & Spray pyrolysis & $250-400$ & 1,000 & 3,040 & 1,000 & $2 \mathrm{~s}$ & 350 & [121] \\
\hline Pd doped $\mathrm{SnO}_{2}$ & $\begin{array}{l}\text { Reactive } \\
\text { Magnetron } \\
\text { sputtering }\end{array}$ & $50-300$ & $10-1,000$ & 85 & 1,000 & several mins & 200 & {$[60]$} \\
\hline $\mathrm{SnO}_{2}$ & Sol-gel annealing & $90-220$ & 1,000 & 2,000 & 1,000 & $15 \mathrm{~s}$ & 150 & {$[66]$} \\
\hline $\begin{array}{l}\text { Al-doped } \\
\mathrm{ZnO}\end{array}$ & $\begin{array}{l}\text { HF magnetron } \\
\text { sputtering }\end{array}$ & $40-100$ & $1,000-5,000$ & 10 & 1,000 & $10 \mathrm{~min}$ & 100 & {$[76]$} \\
\hline $\begin{array}{l}\mathrm{ZnO} \text { wirelike } \\
\text { thin film }\end{array}$ & $\begin{array}{l}\text { Thermal } \\
\text { oxidation }\end{array}$ & 200 & 200 & 2.83 & 200 & $1.5 \mathrm{~min}$ & 200 & {$[68]$} \\
\hline $\mathrm{ZnO}$ & $\begin{array}{l}\text { Thermal } \\
\text { oxidation }\end{array}$ & 400 & $40-160$ & 4,000 & 160 & $1,000 \mathrm{~s}$ & 400 & [122] \\
\hline $\begin{array}{l}\text { Mg-doped } \\
\mathrm{ZnO}\end{array}$ & PLD & $150-300$ & $5-5,000$ & 50 & 5,000 & $5 \min$ & 300 & [77] \\
\hline $\begin{array}{l}\text { Nanoporous } \\
\mathrm{TiO}_{2}\end{array}$ & $\begin{array}{l}\text { Thermal } \\
\text { oxidation }\end{array}$ & 500 & $5-500$ & 10 & 500 & $10 \mathrm{~s}$ & 500 & {$[11]$} \\
\hline $\begin{array}{l}\text { Nanoporous } \\
\mathrm{TiO}_{2}\end{array}$ & Anodic oxidation & $100-300$ & $1,200-10,000$ & 1.24 & 10,000 & - & 225 & {$[67]$} \\
\hline Anatase $\mathrm{TiO}_{2}$ & $\begin{array}{l}\text { Micro-arc } \\
\text { oxidation }\end{array}$ & $100-300$ & 1000 & 2.5 & 1,000 & $45 \mathrm{~s}$ & 250 & {$[71]$} \\
\hline $\begin{array}{l}\mathrm{Nb}_{2} \mathrm{O}_{5} \mathrm{NW} \\
\text { thin film }\end{array}$ & $\begin{array}{l}\text { Thermal } \\
\text { oxidation }\end{array}$ & 20 & $100-2,000$ & 50 & 2,000 & $<2 \min$ & 20 & [69] \\
\hline $\begin{array}{l}\text { MWCNT- } \\
\text { doped WO3 }\end{array}$ & $\begin{array}{l}\text { Electron beam } \\
\text { evaporation }\end{array}$ & $200-400$ & $100-50,000$ & 3 & 1,000 & - & 350 & {$[81]$} \\
\hline
\end{tabular}


Table 1. Cont.

\begin{tabular}{|l|l|c|c|c|c|c|c|c|}
\hline \multirow{2}{*}{ Materials } & \multicolumn{1}{|c|}{$\begin{array}{c}\text { Synthesis } \\
\text { Method }\end{array}$} & \multirow{2}{*}{$\begin{array}{c}\text { Working } \\
\text { Temp. }\left({ }^{\circ} \mathbf{C}\right)\end{array}$} & $\begin{array}{c}\text { Detected } \\
\text { Conc. }(\mathbf{p p m})\end{array}$ & $\boldsymbol{S}_{\max }$ & $\begin{array}{c}\text { Conc. } \\
(\mathbf{p p m})\end{array}$ & $\mathbf{t}_{\text {response }}$ & $\begin{array}{c}\text { Temp. } \\
\left({ }^{\circ} \mathbf{C}\right)\end{array}$ & Ref. \\
\hline Pd-doped $\mathrm{WO}_{3}$ & Sol-gel annealing & $20-350$ & $1,000-1,300$ & $10^{4}$ & 1,000 & $<100 \mathrm{~s}$ & 20 & {$[78]$} \\
\hline $\mathrm{Pt}-$ doped $\mathrm{WO}_{3}$ & $\begin{array}{l}\text { RF magnetron } \\
\text { sputtering }\end{array}$ & $95-220$ & $30-200$ & 9.5 & 200 & $0.7 \mathrm{~min}$ & 200 & {$[123]$} \\
\hline $\mathrm{CuO}$ & Thermal oxidation & $300-800$ & 60,000 & 3.72 & 60,000 & $5 \mathrm{~min}$ & 250 & {$[72]$} \\
\hline $\mathrm{NiO}$ & PLD & $25-250$ & 30,000 & $\begin{array}{c}1.16(\mathrm{n}) \\
1.76(\mathrm{p})\end{array}$ & 30,000 & $10 \mathrm{~min}$ & 125 & {$[124]$} \\
\hline $\mathrm{NiO}$ & $\begin{array}{l}\text { Magnetron } \\
\text { sputtering }\end{array}$ & $300-650$ & $500-10,000$ & $190(\mathrm{p})$ & 5,000 & $5 \mathrm{~min}$ & 400 & {$[74]$} \\
\hline
\end{tabular}

Figure 6. The resistance changes of sol-gel derived $\mathrm{SnO}_{2}$ thin film sensor during long-term exposure in hydrogen containing environment at $150{ }^{\circ} \mathrm{C}$ (reprinted from [66] with permission from Elsevier).

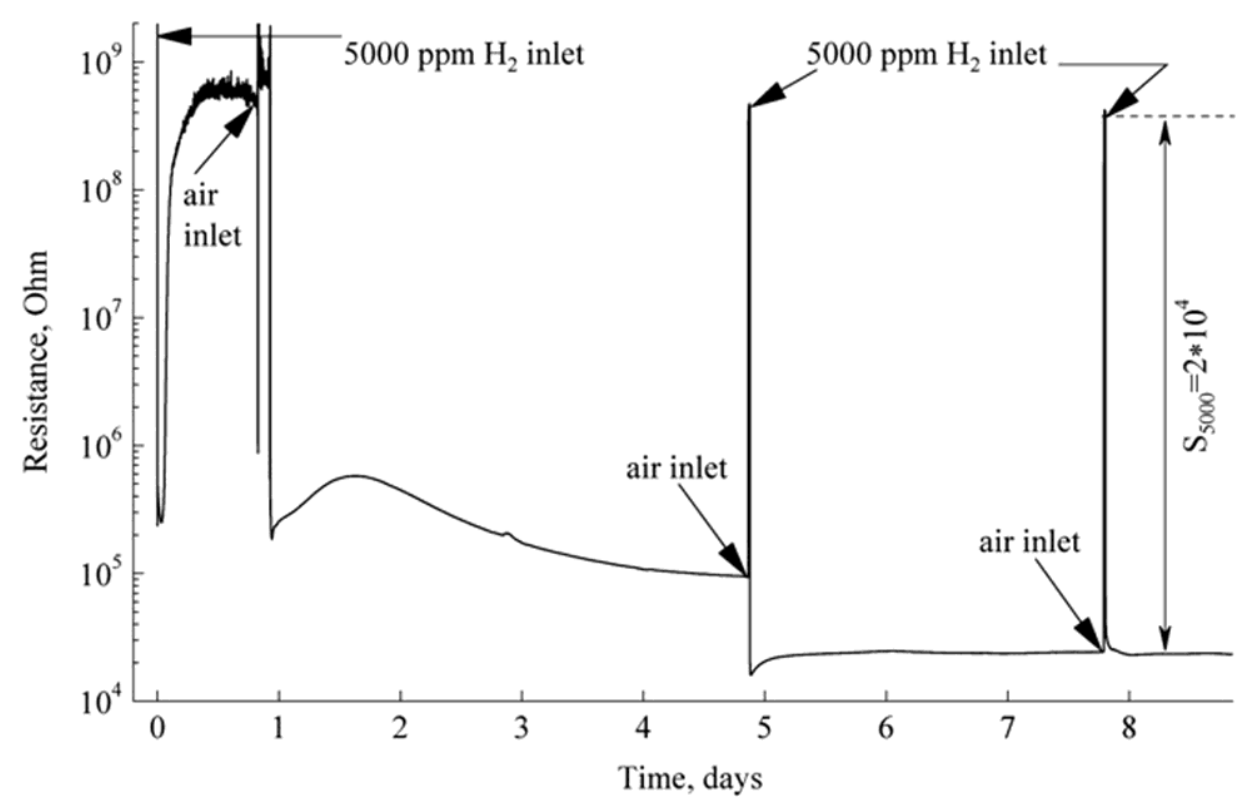

The sensing performance can be modified by the intrinsic character of the SMOs, e.g., the specific surface area. A feasible method to increase the specific surface area of the SMOs thin films is to employ nanoporous thin films as sensing materials, for instance, the $\mathrm{TiO}_{2}$ nanoporous thin films and nanotube arrays. Chen and co-workers have reported a nanoporous $\mathrm{TiO}_{2}$ rutile thin film made by using a nanoporous anodized aluminum oxide (AAO)-assisted fabrication process. They found that the sensitivity was significantly enhanced by the increased specific surface area of the $\mathrm{TiO}_{2}$ thin film due to the shaping of the porous AAO substrate [11]. Similar results of $\mathrm{TiO}_{2}$ and $\mathrm{Nb}_{2} \mathrm{O}_{5}$ nanoporous materials were also reported by Sadek [67] and Hyodo [14] et al.

Besides the porous thin films, thin films composed of NWs with high specific surface area can also be used for hydrogen gas sensing. Hung and co-workers have investigated the hydrogen gas sensing properties of $\mathrm{ZnO}$ wire-like thin films synthesized by thermal oxidation [68]. The films exhibited a sensitive and fast hydrogen response to $200 \mathrm{ppm}$ of hydrogen gas in air at $200{ }^{\circ} \mathrm{C}$. Recently, our 
group has demonstrated a RT hydrogen sensor based on $\mathrm{Nb}_{2} \mathrm{O}_{5} \mathrm{NW}$ thin films [69]. The NW thin film was synthesized by a thermal oxidation of $\mathrm{Nb}$ foil at $900{ }^{\circ} \mathrm{C}$, which was composed of interlacing $\mathrm{Nb}_{2} \mathrm{O}_{5}$ NWs with 30-50 nm in diameter. As shown in Figure 7, the sensor shows a sensitive response to 100-2,000 ppm of hydrogen gas in air at RT. The response time ( $<5 \mathrm{~min})$, however, is still in need of further improvement, which may be due to the slower response from the grain boundaries at the contact site between the NWs than that from surface reaction under RT.

Figure 7. The RT hydrogen sensing properties of $\mathrm{Nb}_{2} \mathrm{O}_{5} \mathrm{NW}$ thin films. (a) Schematic diagram; (b) response to 2,000 ppm of hydrogen in air; (c) hydrogen concentration dependent response; (d) selective response against CO (reprinted from [69] with permission from Elsevier).

(a)

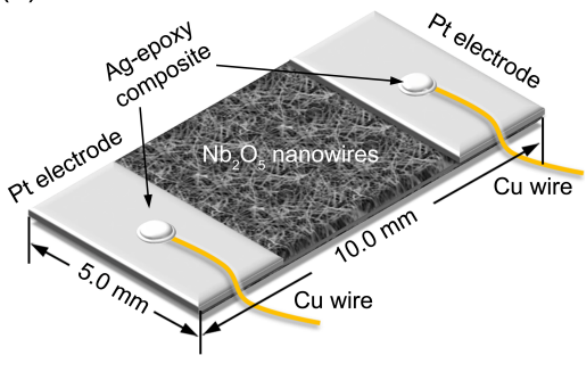

(c)

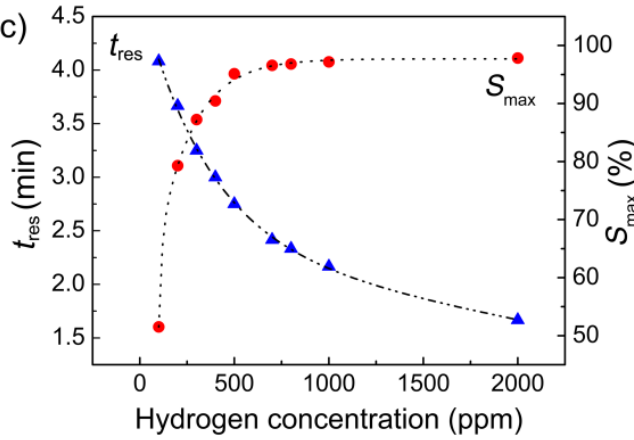

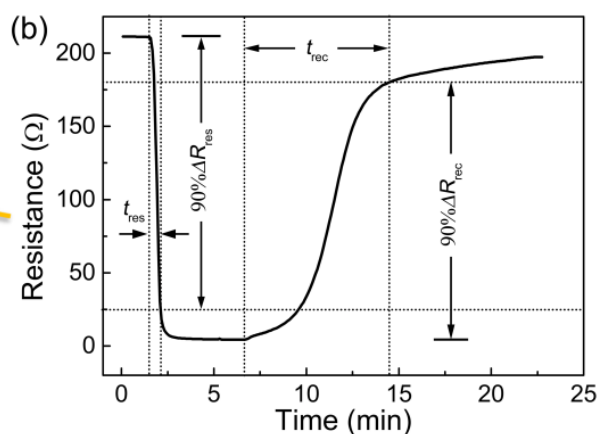

(d)

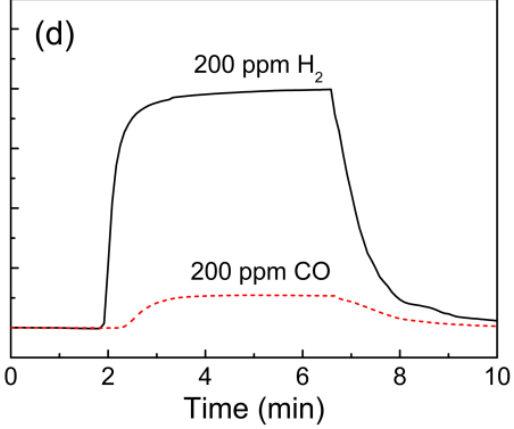

Moreover, the hydrogen sensing behavior can also be affected by the orientation of the SMO thin films. For instance, Choi et al. have reported the hydrogen sensing properties of highly oriented $\mathrm{SnO}_{2}$ thin films. They found that the (101) oriented $\mathrm{SnO}_{2}$ films grown on (112̄0) $\mathrm{Al}_{2} \mathrm{O}_{3}$ substrates exhibited higher hydrogen gas response $\left(S=R_{0} / R_{\mathrm{g}}\right)$ of $\sim 300$ to $10,000 \mathrm{ppm}$ of hydrogen than (002) and (101) oriented ones grown on $(10 \overline{1} 0)$ and (1102) $\mathrm{Al}_{2} \mathrm{O}_{3}$ substrates, respectively. According to the Auger electron spectroscopy (AES) and X-ray photoelectron spectroscopy (XPS) analysis results, the large difference on the sensitivity between two (101) oriented films grown on (11,20) and (1 $\overline{1} 02) \mathrm{Al}_{2} \mathrm{O}_{3}$ should be due to the presence of the $\mathrm{Sn}^{2+}$ component $(\mathrm{SnO})$ at the near surface region along with the $\mathrm{Sn}^{4+}$ component $\left(\mathrm{SnO}_{2}\right)$ by the Auger electron spectroscopy [70].

Besides, the grain boundaries of $\mathrm{TiO}_{2}$ thin film hydrogen sensors were also taken into account by Ling and co-workers. They fabricated $\mathrm{TiO}_{2}$ thin films by a micro-arc oxidation process and found that the maximum gas response of the sensor is estimated to be 2.5 and the response time is $45 \mathrm{~s}$ at $250{ }^{\circ} \mathrm{C}$, but no gas response was seen above $300{ }^{\circ} \mathrm{C}$. According to the electrochemical impedance spectroscopy (EIS) analysis results, the authors suggested that the lower gas response at higher temperature was caused by the disappearance of the depletion layers at the grain boundaries [71]. 
Most SMOs used as hydrogen sensing materials are n-type semiconductors, while $\mathrm{CuO}$ and $\mathrm{NiO}$ with $p$-type conduction can also be employed for hydrogen sensing. Hoa et al. synthesized p-type semiconducting $\mathrm{CuO}$ thin films by deposition and thermal oxidation of $\mathrm{Cu}$ on $\mathrm{SiO}_{2}$ substrates [72]. As reported, the p-type semiconducting property is due to the $\mathrm{Cu}$ vacancies in the crystal structure $\left(\mathrm{Cu}_{1-\delta} \mathrm{O}\right)$ [73]. The $\mathrm{CuO}$ thin films showed increased resistance upon exposure to a hydrogen-containing environment. Except for the first intense hydrogen response, however, the sensor showed no response at all after the hydrogen dilution by $\mathrm{N}_{2}$ gas, as shown in Figure 8 . This result demonstrated the key role of oxygen adsorbed on the surfaces of the $\mathrm{CuO}$ sensor materials, and provided a typical example showing no reaction with hydrogen without mediation via oxygen. Steinebach and co-workers also reported the p-type hydrogen sensing behavior of $\mathrm{NiO}$ thin films at elevated temperatures $\left(\mathrm{T}>500{ }^{\circ} \mathrm{C}\right.$ ) [74]. They found that the gas response of the $\mathrm{NiO}$ thin films was correlated to the surface roughness. A highest response could be obtained at the thin film with highest surface roughness due to the high specific surface area offering more surface adsorption site for oxygen from the gas phase. In addition, a tunable gas sensing behavior of $\mathrm{ZnO}$ thin films between $\mathrm{p}$-type and n-type were reported by Kobrinsky and co-workers [75]. This work indicates that the exposure to hydrogen gas may invert the sensor between $\mathrm{p}$ - and n-type in a fast and reversible manner.

Figure 8. The response-and-recovery behaviors of $\mathrm{CuO}$ thin film oxidized at $400{ }^{\circ} \mathrm{C}$ in different dilution gases of (a) dry air and (b) nitrogen at $250{ }^{\circ} \mathrm{C}$ (reprinted from [72] with permission from Elsevier).
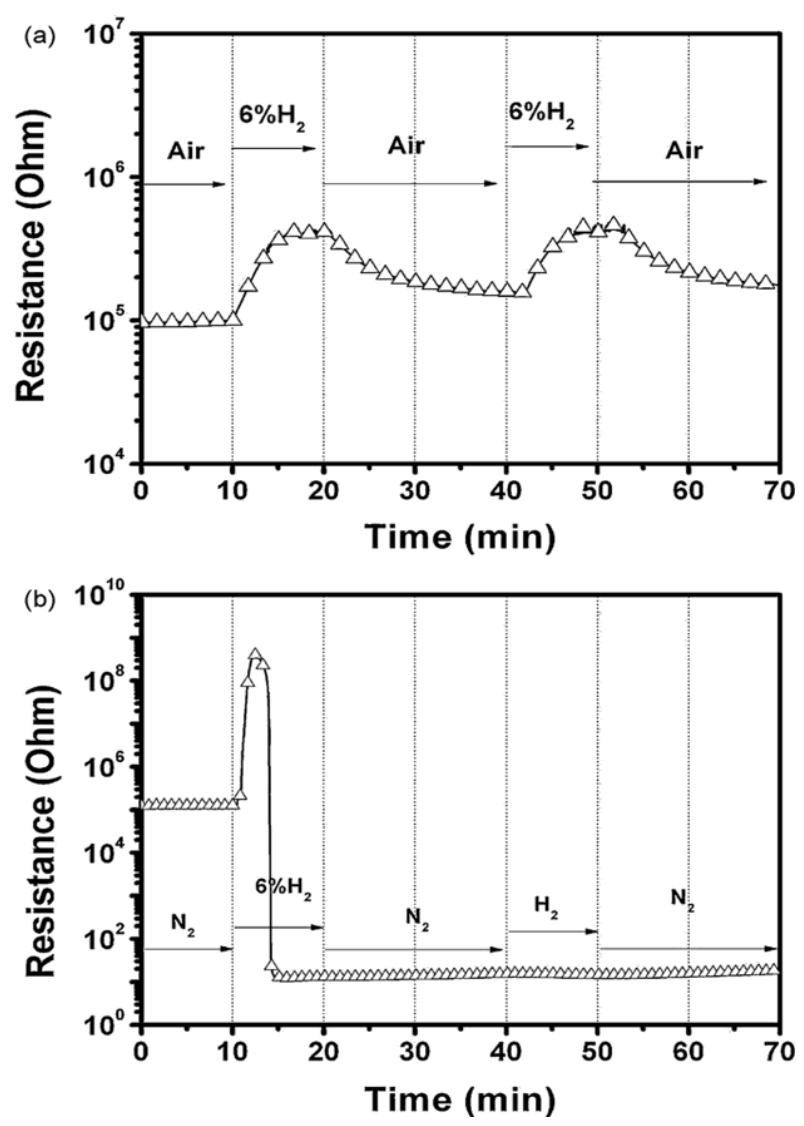

Besides the intrinsic character of SMO thin films, the hydrogen sensing properties can also be improved by other approaches, e.g., by doping, compositing with noble metal nanoparticles, as well as 
adjusting of electrode parameters, etc. Among them, doping is an effective method to modify the sensing performance of SMOs. Galstyan et al. investigated the hydrogen sensor of Al-doped $\mathrm{ZnO}$ thin film, which have high sensitivity to low concentrations of hydrogen in air (1,000 ppm) [76]. Liu et al. have reported a great enhancement of the hydrogen sensing performance of $\mathrm{ZnO}$ thin films by $\mathrm{Mg}$ doping, and suggested that the higher sensitivity of $\mathrm{Mg}$-doped $\mathrm{ZnO}$ thin films should be due to the larger resistance [77]. Moreover, Palladium (Pd) has already been used for doping in SMOs due to its outstanding catalytic properties. Shen et al. have reported $\mathrm{Pd}$-doped $\mathrm{SnO}_{2}$ thin films with columnar nanostructures and their hydrogen sensing properties [60]. The thin films were deposited by reactive magnetron sputtering of a $\mathrm{Pd} / \mathrm{Sn}$ target. Their results proved that Pd-doping can enhance the sensitivity of the $\mathrm{SnO}_{2}$ thin film to hydrogen gas at $300{ }^{\circ} \mathrm{C}$, which was attributed to the so-called chemical and electronic effects. Moreover, the columnar nanostructures were also considered to play an important role for improving the sensing performance due to the higher specific surface area and increasing of the surface Schottky-barrier-limited electron transportation. Fardindoost et al. also demonstrated the hydrogen sensing of Pd-doped $\mathrm{WO}_{3}$ thin films prepared by a sol-gel process [78]. They suggested that $\mathrm{Pd}$ can modify the growth kinetic of $\mathrm{WO}_{3}$ nanoparticles by reducing the crystallite size and therefore improve the hydrogen sensitivity. As shown in Figure 9, the hydrogen sensitivity increased as increasing the $\mathrm{Pd}$ doping concentration in the whole temperature range (30 to $350{ }^{\circ} \mathrm{C}$ ), which could be attributed to a decrease in $\mathrm{WO}_{3}$ crystal size and the effect of Pd catalyst in performing electronic sensitization mechanism. In addition, the sensitivity increases by decreasing the operating temperature. They attributed that to a reduction of the activation energy between the $\mathrm{WO}_{3}$ surface and the hydrogen gas in the presence of $\mathrm{Pd}(\mathrm{PdO})$. The sensitivity is up to $2.5 \times 10^{4}$ at $\mathrm{RT}$ under exposure to 1,000 ppm of hydrogen in air, and the sensor exhibited its optimum sensing performance at $100{ }^{\circ} \mathrm{C}$ due to the better response and recovery time as well as the better temperature stability to the environment. Similar results were also reported by Zhang et al. of their Pt-doped $\mathrm{WO}_{3}$ thin films.

Figure 9. The temperature dependent sensitivity to $1,300 \mathrm{ppm}$ of hydrogen gas in air of $\mathrm{Pd} / \mathrm{WO}_{3}$ thin film (reprinted from [78] with permission from Elsevier).

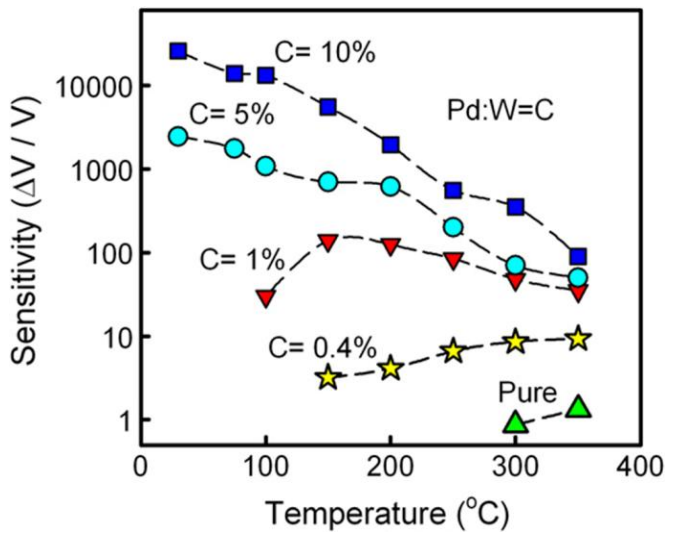

Besides doping effects, noble metal nanoparticles ( $\mathrm{Pd}, \mathrm{Pt}$ and $\mathrm{Au}$, etc.) were also used for improving the gas sensing performance of SMOs due to their catalytic properties. Fasaki et al. have demonstrated the effect of $\mathrm{Au}$ and $\mathrm{Pt}$ nanoclusters on the hydrogen sensing properties of $\mathrm{SnO}_{2}$ thin films [79]. The addition of metal nanoparticles was found to decrease the detection limit and the operating temperature (from $180{ }^{\circ} \mathrm{C}$ to $85^{\circ} \mathrm{C}$ ), while increasing the sensing response signal. In the 
presence of $\mathrm{Au}$ or Pt nanoclusters on the surface, the hydrogen gas would split up into hydrogen atoms by the catalytic process. The rapid transfer of the adsorbed dissociated hydrogen atoms mediated by the metal nanoclusters, which is known as a spill-over effect, leads to an increase in the rate of interaction with $\mathrm{SnO}_{2}$, and results in the enhanced hydrogen sensing performance.

Recently, carbon nanotubes were used as doping additives in SMO thin films. Gong and co-workers fabricated micromachined sol-gel single wall carbon nanotube (SWCNT)/SnO ${ }_{2}$ nanocomposite thin films and found that the hydrogen sensing performance of the $\mathrm{SWCNT} / \mathrm{SnO}_{2}$ sensors was better than that of the pure $\mathrm{SnO}_{2}$ sensor, including higher sensitivity, lower working temperature, and shorter response/recovery time [80]. The greatly improved performances are mainly attributed to the effective gas accessing nanopasses through SWCNT plus the smaller distance between adjacent gas accessing boundaries formed by the distribution of tiny SWCNTs. Wongchoosuk and co-workers reported their research works about the MWCNT-doped $\mathrm{WO}_{3}$ thin films with higher sensitivity and selectivity to hydrogen, as well as reduced operating temperatures [81]. They suggested that the creation of nanochannels and formation of $p$ - $n$ heterojunctions were responsible for the enhanced sensing behavior.

As reported by Seal and co-workers, the electrode architecture is important to the hydrogen sensing performance of the SMO thin film sensors, because of the increased activation energy that may impede the overall sensor response at lower temperatures (especially RT) [82-84]. Both the experimental results and the theoretical study using a diffusion reaction model suggested the electrode spacing-dependent $(2-20 \mu \mathrm{m})$ response kinetics of the nano-micro-integrated hydrogen sensor at RT, which should be due to the reduced path length for free electrons

Although most investigations have focused on improvement of sensing performance of the resistance type sensors in recent years, there were also some studies on the hydrogen sensing of Schottky diode, MOS capacitor, optical and acoustic type SMO thin film sensors. For instance, Shafiei, $\mathrm{Yu}$ and co-workers have demonstrated the $\mathrm{Pt} /$ nanostructure $\mathrm{ZnO}$ and $\mathrm{Pt} / \mathrm{ZnO} / \mathrm{SiC}$ based Schottky diode based hydrogen sensors $[33,85,86]$. They all found that a larger voltage shift was produced by the sensor under reverse bias conditions than under forward bias conditions. As explained by Shafiei, this is caused by the increase in free carrier concentration and the decrease in permittivity, which can be enhanced by the augmented localized electric fields produced by the nanostructures. $\mathrm{TiO}_{2}$ and $\mathrm{Nb}_{2} \mathrm{O}_{5}$ nanoporous thin film were also employed as semiconductor layers to fabricate Schottky diode type hydrogen sensors, which exhibited outstanding sensing properties due to the high specific surface area and catalytic behavior of $\mathrm{Pd}$ electrodes [9,14]. Yadav et al. reported a $\mathrm{Pd} / \mathrm{TiO}_{2} / \mathrm{Si} \mathrm{MOS}$ capacitor hydrogen sensor with very large parallel shift in $C-V$ and $G-V$ characteristics, which appears to be basically due to the high polarizability of $\mathrm{TiO}_{2}$ lattice and increase in interface trap charges in presence of hydrogen gas and could be used for RT hydrogen sensing [46].

Acoustic wave hydrogen sensors have advantages that allow for remote wireless operation and possess high potential application possibility on passive sensors. Recently, Phan and Chung reported their research work on a SAW hydrogen sensor based on $\mathrm{ZnO}$ nanoparticle thin films [87]. They deposited a $\mathrm{Pt} / \mathrm{ZnO}$ sensing layer on the SAW delay line sensor based interdigital electrodes/AlN/Si structure. A maximum frequency down shift of $55 \mathrm{kHz}$ was observed when the layered sensor was exposed to $10,000 \mathrm{ppm}$ of hydrogen gas at RT, which is three times higher than the conventional SAW sensor. 
Unlike the electrical hydrogen sensors, the optical hydrogen sensors are fabricated by the coating of SMO thin films on the surface of the optical fiber. Yan and co-workers have demonstrated a $\mathrm{SnO}_{2}$ thin film-based optical fiber hydrogen sensor [88]. The $\mathrm{SnO}_{2}$ coating induced an optical absorption peak centering at around $320 \mathrm{~nm}$ when the $\mathrm{SnO}_{2}$-coated optical fiber were exposed to $\mathrm{H}_{2}-\mathrm{N}_{2}$ gas at a temperature higher than $300{ }^{\circ} \mathrm{C}$. The absorbance increased as the hydrogen concentration increased. Besides, high hydrogen selectivity was also observed with no optical absorption response to other reducing gases including $\mathrm{CO}$ and $\mathrm{CH}_{4}$. Moreover, $\mathrm{TiO}_{2}$ thin films with the assistance of $\mathrm{Pd}$ were also used as SMOs in optical hydrogen sensors. Yang and co-workers demonstrated an optical fiber hydrogen sensor based on side-polished fibers with $\mathrm{Pd} / \mathrm{WO}_{3}$ thin film coating [89]. This sensor operated based on the evanescent field interaction mechanism, and showed an increase of transmitted power when hydrogen concentration increases. In addition, sensors based on multimode fibers shows higher sensitivity but lower response linearity to hydrogen concentration than sensors based on single mode fibers.

\subsection{D Nanostructures}

Compared to SMO thin films, 1D SMO nanostructures such as NWs, NRs, nanobelts and nanotubes, possess higher specific surface areas and unique 1D structures [90,91], which lead to better gas sensing properties including ultra-high sensitivity, fast response, low working temperature and LOD, as well as good long-term operation performances $[4,15,16]$. In recent years, the number of investigations on hydrogen sensors based on 1D SMO nanostructures has grown rapidly with the development of large scale synthesis processes and micro-/nano-scale fabrication techniques. Several kinds of sensor architectures were also developed based on the difference of fabrication techniques to investigate the hydrogen gas sensing behavior of individual or aligned multiple 1D nanostructures.

\subsubsection{Individual SMO 1D Nanostructures}

By means of the rapid development of nano-fabrication technique, hydrogen sensors based on individual NWs were fabricated by letting the NW bridging crossover the nano-scale electrodes either through the focused ion beam (FIB), electron beam lithography (EBL) process or by the dielectrophoresis (DEP) controlling. As a result, nearly all these hydrogen sensors are based on the resistance variation with the exposure to hydrogen containing atmosphere. Table 2 lists the sensing performance of recently developed hydrogen sensors based on individual SMO 1D nanostructures.

Table 2. The hydrogen sensing performance of recent developed individual 1D SMO nanostructures with resistance type response.

\begin{tabular}{cccccc}
\hline Materials & Working Temp. $\left({ }^{\circ} \mathbf{C}\right)$ & $\boldsymbol{S}_{\max }$ & Conc. $(\mathbf{p p m})$ & t $_{\text {response }}$ & Ref. \\
\hline $\mathrm{SnO}_{2}$ nanobelt & $\mathrm{RT}-80$ & $2($ at RT $)$ & 20,000 & $220 \mathrm{~s}$ & {$[92]$} \\
$\mathrm{ZnO} \mathrm{NR}$ & $\mathrm{RT}$ & 1.02 & 150 & $1 \mathrm{~min}$ & {$[93,94]$} \\
$\mathrm{ZnO} \mathrm{NW}$ & $\mathrm{RT}$ & 1.5 & 100 & $64 \mathrm{~s}$ & {$[95,96]$} \\
$\mathrm{SnO}_{2} \mathrm{NR}$ & $\mathrm{RT}-350$ & $13\left(\right.$ at $\left.250^{\circ} \mathrm{C}\right)$ & 100 & - & {$[97]$} \\
$\mathrm{ZnO} \mathrm{NR}_{\mathrm{TiO}_{2} \mathrm{NR}}$ & $\mathrm{RT}$ & 10 & 1,000 & - & \\
$\mathrm{WO}_{2.72} \mathrm{NR}$ & $\mathrm{RT}$ & 8 & 1,000 & - & {$[98]$} \\
\hline
\end{tabular}


A similar feature of the resistance-type hydrogen sensors based on individual SMO 1D nanostructure is the outstanding RT operation performance. For instance, Fields and co-workers have reported their RT hydrogen sensor with low power consumption, which is based on the individual $\mathrm{SnO}_{2} \mathrm{NW}$ connected by a pair of $\mathrm{RuO}_{2}$ nano-electrodes [92]. Without any functionalization with catalyst, the sensor shows a response of $S=60 \%\left(S=\Delta R / R_{0}\right)$ at $25{ }^{\circ} \mathrm{C}$ to $20,000 \mathrm{ppm}$ of hydrogen in air with a response and recovery time of approximately $220 \mathrm{~s}$. The RT sensing performance of the unfunctionalized $\mathrm{SnO}_{2} \mathrm{NW}$ is much better than that of the pure $\mathrm{SnO}_{2}$ nanostructured thin films, and is believed to be further improved by surface functionalization of the catalyst.

Lupan and co-workers have reported a series of research works about hydrogen sensors based on individual $\mathrm{ZnO} 1 \mathrm{D}$ nanostructurea connected by nano-electrodes fabricated through a FIB process [93-96]. The hydrogen gas nanosensor based on two-terminated single ZnO NR (tripod/dipod) that they reported in 2007 and 2008 exhibited a response of $2 \%$ and $4 \%\left(S=\Delta R / R_{0}\right)$ with a short response time of $1 \mathrm{~min}$ to 150 and $200 \mathrm{ppm}$ of hydrogen in air under RT, respectively [93,94]. Furthermore, the sensitivity to several common gases like $\mathrm{O}_{2}, \mathrm{CH}_{4}, \mathrm{CO}$, and LPG were less than $0.02 \%$ and $0.25 \%$ under the same conditions respectively, which indicated the high selectivity of hydrogen. Owing to the RT operation, the working power is very low $(<5 \mu \mathrm{W})$, compared with thin film based sensors.

Figure 10. The SEM image of dispersed (a) and connect $\mathrm{ZnO} \mathrm{NWs}$ with $200 \mathrm{~nm}$ (b) and $100 \mathrm{~nm}$ (c) in diameter; (d) Transient response of the $100 \mathrm{~nm} \mathrm{ZnO} \mathrm{NW}$-based sensor to $100 \mathrm{ppm}$ of $\mathrm{H}_{2}$ gas at $\mathrm{RT}\left(22{ }^{\circ} \mathrm{C}\right)$ (reprinted from reference [96] with permission from Elsevier).

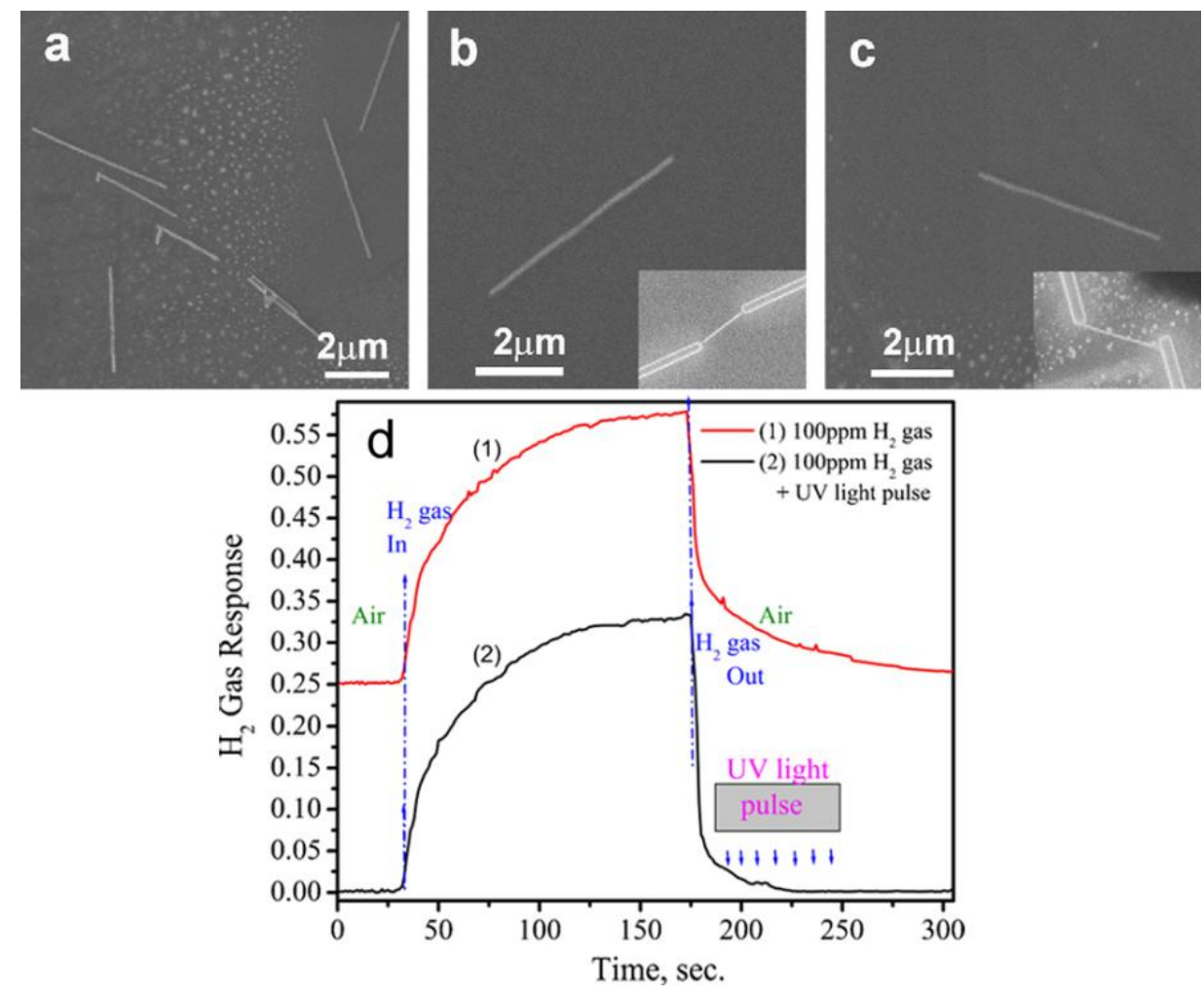

They also fabricated hydrogen nanosensors based on individual $\mathrm{ZnO} \mathrm{NW}$ s connected by $\mathrm{Cr} / \mathrm{Au}$ nanoelectrodes on both ends $[95,96]$. They investigated the photoluminescence spectra of the thermally 
treated $\mathrm{ZnO}$ NWs in a hydrogen environment at $400{ }^{\circ} \mathrm{C}$, and found that the concentration of defects responsible for visible emission from $\mathrm{ZnO} \mathrm{NW}$ was reduced by annealing in a hydrogen atmosphere, which means a passivation of recombination centers. The author indicated that this effect may lead to the reduction of hydrogen response and should be taken into account when analyzing the long-term stability of the NW based sensors. Therefore, the development of RT sensors is necessary. Besides the outstanding RT performance on hydrogen sensing as shown in Figure 10, the ZnO NW sensor also exhibited enhanced recovery behavior by employing ultraviolet (UV) light illumination instead of heat treatment to facilitate the desorption of gas species. The outstanding hydrogen performance can be attributed to: (a) the small diameter of $\mathrm{ZnO}$ NWs that means high specific surface area and leads to more surface atoms for surface reaction; (b) the small diameter of ZnO NWs, comparable to the Debye length (a measure of the field penetration into the bulk) that causes the electronic properties to be more influenced by adsorption-desorption processes at the surface; (c) the increased electron and hole diffusion rate to the surface that allows the analyte to be rapidly photo-desorbed from the surface even at RT under UV light pulse; (d) the stoichiometric composition of $\mathrm{ZnO} \mathrm{NW}$ grown by chemical vapor deposition (CVD) with a higher level of crystallinity than multigranular oxides. The author suggested that the operation mode of $\mathrm{ZnO} \mathrm{NW}$ devices can be controlled by the modulation of surface states through surface morphology engineering and size control.

Recently, DEP controlling has been gradually introduced for fabricating individual NW and NW-network based devices. Owing to the small diameter and high aspect ratio, NWs are very easy to control for the alignment between micro- or nano-scale electrodes by adjusting the DEP parameters. Huang et al. have demonstrated a hydrogen sensor based on $\mathrm{SnO}_{2}$ single NR, which is aligned by DEP controlling and fixed by Pt stripes onto the microelectrodes [97]. This sensor shows a fast and selective response to $100 \mathrm{ppm}$ of hydrogen at RT, but shows its best performance at $250{ }^{\circ} \mathrm{C}$. The good sensing performance of the NR sensors can be attributed to the intrinsically small dimensions of the NR, comparable to the depletion layer. Although DEP can be used for fabricating individual NW/NR based sensors, the control accuracy is much lower than with the FIB or EBL processes, therefore, it is mostly used for fabricating NW/NR networks.

In addition to the FIB and DEP controlling methods, Rout and co-workers have demonstrated the hydrogen sensing characteristics of single $\mathrm{NWs}$ of $\mathrm{ZnO}, \mathrm{TiO}_{2}$ and $\mathrm{WO}_{2.72}$ by contact mode atomic force microscopy (AFM), which actually represents the response from the radial direction of the NWs. All SMO NWs investigated in this work showed fast and sensitive response to 1,000 ppm of hydrogen gases [98].

Baik and co-workers have reported a hydrogen sensor based on the metal-insulator transition (MIT) of Pd-sensitized $\mathrm{VO}_{2} \mathrm{NW}$, as shown in Figure 11 [99]. By biasing the NW judiciously so that its temperature is just below the metal-insulator transition temperature, even trace amounts of hydrogen induce the metal-insulator transition, producing an almost three order of magnitude increase in the current through the NW. The authors suggested that the large change in the MIT transition temperature of $\mathrm{VO}_{2}$ may result from the formation of hydrogen interstitials or from the formation of adsorbed $\mathrm{OH}$, which act as electron donors that increase the carrier density in the conduction band. Two processes during hydrogen response were illustrated. During a rapid initial process, the insulator to metal transition temperature is decreased by $>10^{\circ} \mathrm{C}$ even when exposed to trace amounts of hydrogen gas. Subsequently, hydrogen continues to diffuse into the $\mathrm{VO}_{2}$ for several hours before saturation is 
achieved with only a modest change in the insulator to metal transition temperature but with a significant increase in the conductivity. The two time scales over which hydrogen-related processes occur in $\mathrm{VO}_{2}$ likely signal the involvement of two distinct mechanisms influencing the electronic structure of the material, one of which involves electron-phonon coupling pursuant to the modification of the vibrational normal modes of the solid by the introduction of $\mathrm{H}$ as an impurity.

Figure 11. (a) SEM image of an individual $\mathrm{VO}_{2} \mathrm{NW}$ device with appropriate Ohmic contacts (b) SEM image of a Pd-decorated $\mathrm{VO}_{2} \mathrm{NW}$; (c) $I$ - $V$ curves obtained at $50{ }^{\circ} \mathrm{C}$ for Pd-decorated $\mathrm{VO}_{2} \mathrm{NW}$ after various exposure times to hydrogen gas (5 sccm), added to the background argon stream (10 sccm); (d) The change in current for a Pd-decorated $\mathrm{VO}_{2}$ $\mathrm{NW}$ biased at $10 \mathrm{~V}$ as a function of time of exposure to hydrogen gas (reprinted from [99] with permission from The American Chemical Society).
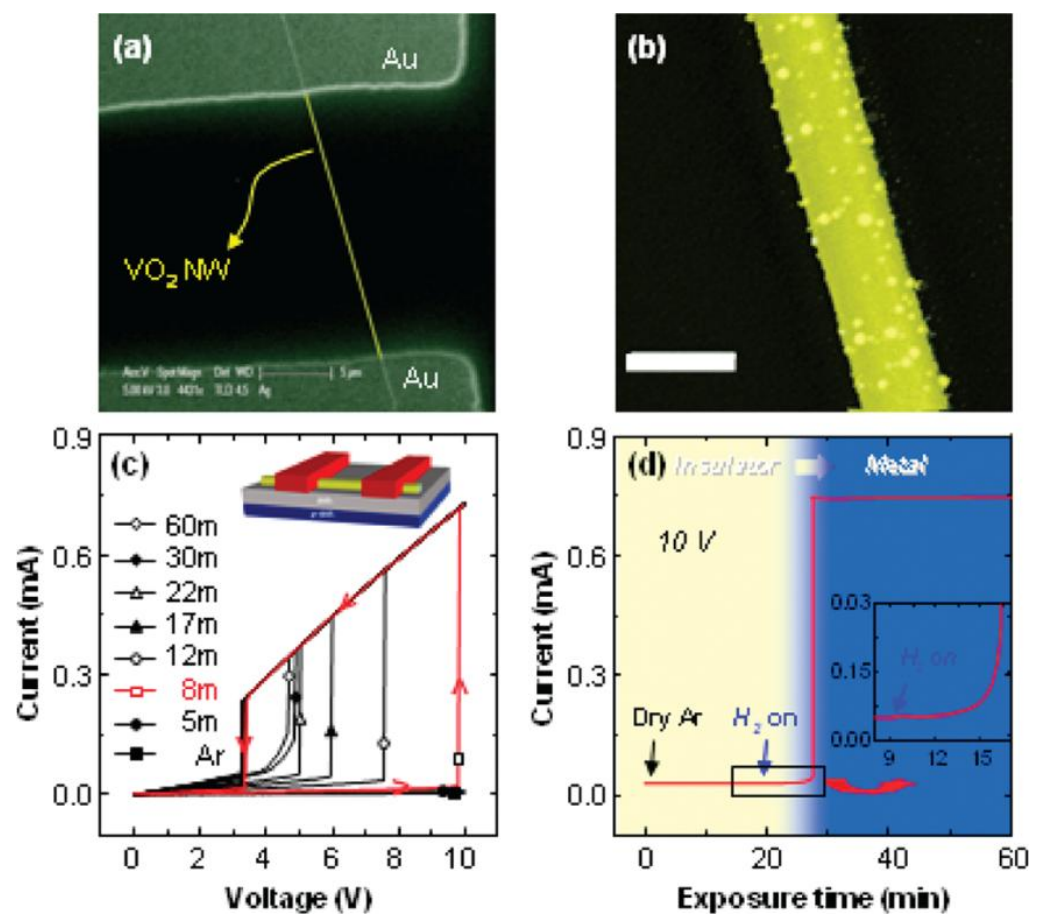

\subsubsection{Multiple SMO 1D Nanostructures}

Unlike the individual 1D nanostructure based sensors, sensors based on multiple SMO 1D nanostructures do not need precise nano-fabrication techniques to connect the nanostructures. The relatively simple fabrication technique may greatly decrease the manufacturing costs and increase the repeatability of the sensors with outstanding sensing performance, which is more suitable for practical applications. Table 3 lists the hydrogen sensing performance of recently developed 1D SMO nanostructure networks with resistance type response.

Wang and co-workers have demonstrated an on-chip self-assembled $\mathrm{SnO}_{2} \mathrm{NW}$ hydrogen sensor with $\mathrm{SnO}_{2} \mathrm{NWs}$ extending from one side to the other of the comb-shape interdigital electrodes, which is shown in Figure 12 [100]. With the decreasing gap between the electrodes, the spatial density of the $\mathrm{SnO}_{2} \mathrm{NWs}$ is higher. The sensor response is enhanced because of the geometric effect associated with the high electrode spatial density. Thus, the sensor response of the $\mathrm{SnO}_{2} \mathrm{NW}$ sensor with a gap of $20 \mu \mathrm{m}$ is higher than that of the $\mathrm{SnO}_{2} \mathrm{NR}$ sensor with a gap of $50 \mu \mathrm{m}$. In addition, the $\mathrm{SnO}_{2} \mathrm{NW}$ 
sensor has better gas sensing than that of the $\mathrm{SnO}_{2}$ NR sensor due to the nano-size effect and could be more promising in practical applications. Several other gas sensors with similar structure were also reported [101-103].

Table 3. The hydrogen sensing performance of recent developed 1D SMO nanostructure networks with resistance type response.

\begin{tabular}{|c|c|c|c|c|c|}
\hline Materials & Working Temp. $\left({ }^{\circ} \mathrm{C}\right)$ & $S_{\max }($ Temp.) & Conc. (ppm) & $\mathbf{t}_{\text {response }}$ & Ref. \\
\hline $\mathrm{SnO}_{2} \mathrm{NWs}$ & $200-300$ & $3.3\left(100^{\circ} \mathrm{C}\right)$ & 1,000 & $100 \mathrm{~s}$ & [100] \\
\hline $\mathrm{In}_{2} \mathrm{O}_{3}$ nanopushpins & $150-400$ & $1.1\left(250^{\circ} \mathrm{C}\right)$ & 500 & $35 \mathrm{~s}$ & [105] \\
\hline $\mathrm{In}_{2} \mathrm{O}_{3} \mathrm{NRs}$ & 250 & 1.2 & 1,000 & $48 \mathrm{~s}$ & [108] \\
\hline $\mathrm{ZnO} \mathrm{NWs}$ & 200 & 5.0 & 500 & $65 \mathrm{~s}$ & [106] \\
\hline $\mathrm{In}_{2} \mathrm{O}_{3} \mathrm{NWs}$ & $150-400$ & $1.1\left(200^{\circ} \mathrm{C}\right)$ & 500 & $31 \mathrm{~s}$ & [109] \\
\hline $\mathrm{ZnO} \mathrm{NWs}$ & 200 & 5.3 & 100 & $\sim 1 \mathrm{~min}$ & [110] \\
\hline Pt coated $\mathrm{W}_{18} \mathrm{O}_{49} \mathrm{NWs}$ & 200 & 2.1 & 1,000 & $\sim 1 \mathrm{~min}$ & [120] \\
\hline $\mathrm{In}_{2} \mathrm{O}_{3}-\mathrm{ZnO}$ core-shell $\mathrm{NWs}$ & $100-400$ & $7.0\left(300^{\circ} \mathrm{C}\right)$ & 2,000 & - & [116] \\
\hline ZnO NRs textile & RT & 5.9 & 1,000 & $10 \mathrm{~min}$ & [122] \\
\hline $\mathrm{ZnO} \mathrm{NRs}$ & $325-350$ & $2.0\left(350^{\circ} \mathrm{C}\right)$ & 50 & $6 \mathrm{~s}$ & [127] \\
\hline aligned $\mathrm{ZnO}$ nanotubes & $200-300$ & $3.6\left(300^{\circ} \mathrm{C}\right)$ & 100 & - & [119] \\
\hline $\mathrm{CuO}$ NWs & $200-300$ & $2.0\left(250^{\circ} \mathrm{C}\right)$ & 60,000 & - & [104] \\
\hline $\mathrm{ZnO}$ NWs on carbon microfiber & RT-320 & $5\left(280^{\circ} \mathrm{C}\right)$ & 200 & $8 \mathrm{~s}$ & [121] \\
\hline Pt-doped $\mathrm{SnO}_{2} \mathrm{NWs}$ & RT-300 & $119\left(100{ }^{\circ} \mathrm{C}\right)$ & 1,000 & - & [111] \\
\hline Pd-decorated $\mathrm{SnO}_{2} \mathrm{NWs}$ & $\mathrm{RT}$ & $10^{3}$ & 10,000 & $2 \mathrm{~s}$ & {$[17]$} \\
\hline
\end{tabular}

Figure 12. The SEM and TEM images of the as-fabricated $\mathrm{SnO}_{2} \mathrm{NW}$ gas sensor. low magnifying (a) and high magnifying (b) SEM images; (c) SEM image of the interspace of electrodes; (d) the HRTEM image of one $\mathrm{SnO}_{2} \mathrm{NW}$ and the corresponding SAD pattern (inset) (reprinted from [100] with permission from The American Chemical Society).

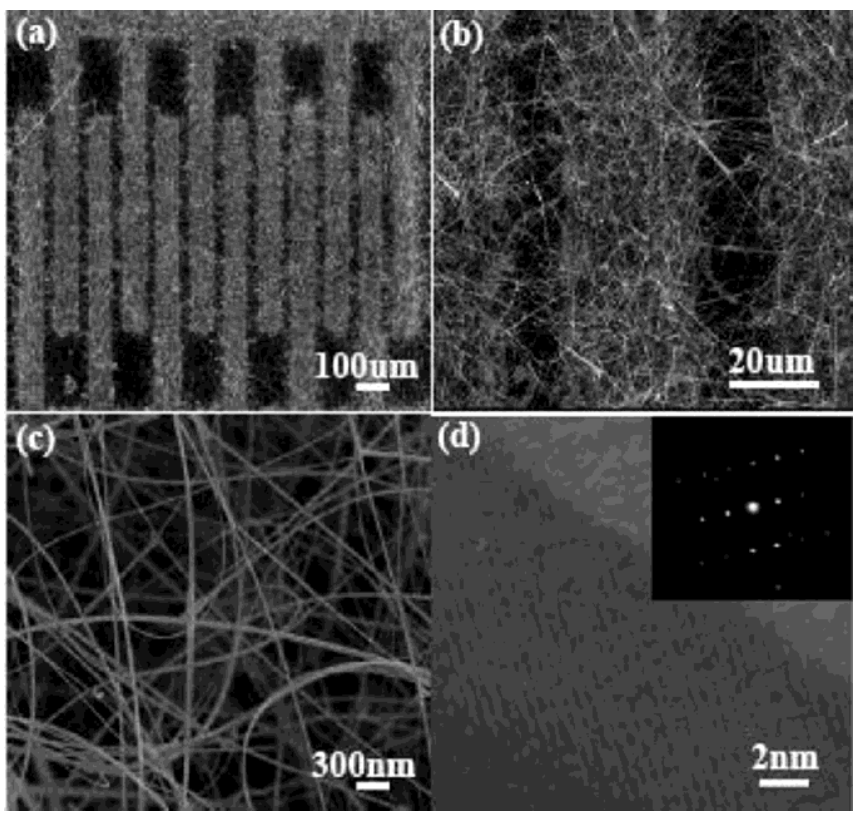

Another commonly used fabrication method of SMO 1D nanostructure network hydrogen sensor is realized by transferring as-synthesized SMO 1D nanostructures by droplets onto a pair of interdigitated 
electrodes. Duc Hoa et al. synthesized p-type semiconducting $\mathrm{CuO}$ NWs by thermal oxidation of copper wire in air and transferred the NWs onto a pair of interdigitated electrodes to fabricate a $\mathrm{CuO}$ NW based hydrogen sensor [104]. The sensor could detect a wide range of gases, including $1 \% \mathrm{H}_{2}$, 60 ppm CO, 60 ppm $\mathrm{NH}_{3}$, and 60 ppm $\mathrm{NO}_{\mathrm{x}}$ at elevated temperatures (200-300 ${ }^{\circ} \mathrm{C}$ ). Qurashi and co-workers have reported their hydrogen sensors based on $\mathrm{In}_{2} \mathrm{O}_{3} \mathrm{NW} /$ nanoneedles and $\mathrm{ZnO}$ NW/NR networks fabricated by this process [105-109]. Among them, $\mathrm{In}_{2} \mathrm{O}_{3} \mathrm{NWs}$ and nanoneedles grown along the (110) direction were synthesized by a catalyst-supported CVD process, and showed fast, reliable and stable hydrogen responses at elevated temperatures $\left(200{ }^{\circ} \mathrm{C}\right)$ [108]. The $\mathrm{In}_{2} \mathrm{O}_{3} \mathrm{NWs}$ showed better sensing performance than nanoneedles, which was attributed to the smaller diameter and high surface-to-volume ratio of the NWs. The authors also suggested that the number of interconnections between the two electrode fingers should be taken into account.

The nanojunction effect to the hydrogen sensing behavior in the interconnected multiple ZnO NWs were investigated by Khan et al. [110]. They used the DEP process to make the ZnO NWs positioned and aligned between two $\mathrm{Ti}$ and $\mathrm{Au}$ electrodes and deposited a top contact electrode of $\mathrm{Ti}$ and $\mathrm{Au}$ for better contact. By controlling the DEP force, they obtained both single and multiple NW devices. Both devices showed n-type semiconductor characteristics, while the multiple NW devices showed greatly enhanced conductance due to increased channels. The sensor response was higher for the multiple $\mathrm{ZnO}$ NWs than the response for the single $\mathrm{ZnO} \mathrm{NW}$ over the entire range of hydrogen concentration. The author attributed that to the nanojunctions acting as potential barriers for electron flow, which decreased as the NW was exposed to the reducing gas, resulting in an increase in the current flow. However, the nanojunction effect also affected the recovery time, which can be attributed to the significant diffusion resistance in the recovery period because of the low diffusivity of oxygen molecules. They suggested that the potential barrier modulation of multiple NWs was more efficient than the modulation of the surface depletion of the single $\mathrm{ZnO} N W$ in gas sensing.

As mentioned above, doping is an efficient method for improving the gas sensing performance of SMO thin films. Furthermore, it is also suitable for improving the sensitivity and response time for SMO 1D nanostructures. For instance, Shen et al. have compared the hydrogen sensing properties of undoped and Pt-doped $\mathrm{SnO}_{2} \mathrm{NWs}$, and found that Pt doping not only improves the sensitivity, but also lowers the operating temperature at which the sensitivity is maximized [111]. Moreover, the sensitivities of Pd-doped $\mathrm{SnO}_{2} \mathrm{NWs}$ are higher than those of Pt-doped $\mathrm{SnO}_{2} \mathrm{NWs}$, especially in the temperature range of $50-250{ }^{\circ} \mathrm{C}$. The difference in the sensing properties of two types of impurity-doped NWs may be attributed to two different effects of "chemical sensitization mechanism" from Pt-doping and "electronic sensitization mechanism" from Pd-doping, respectively. Moreover, doping is more commonly realized for SMO nanofibers synthesized by electrospinning and calcination procedures. The nanofibers were always spin-coated on a ceramic tube with a pair of Au electrodes printed on the surface and a Pt heating wire inserted into the tube to form a side-heated gas sensor, as shown in Figure 13 [112]. For example, Liu, Zhang and co-workers have demonstrated the enhanced hydrogen sensing performance of $\mathrm{Pd}$ and Co doped $\mathrm{SnO}_{2}$ nanofibers [113,114]. When Co was doped in $\mathrm{SnO}_{2}$, high response, short response and recovery times, and good selectivity were observed. The authors suggested that the $\mathrm{Co}_{3} \mathrm{O}_{4}$ grains in $\mathrm{SnO}_{2}$-rich materials will combine with $\mathrm{SnO}_{2}$ electronically by forming $p$ - $n$ junctions, which may explain the large sensor response. However, too much Co-doping would lead to decreased hydrogen response. $\mathrm{Xu}$ and co-workers have investigated the Al doping effect on the 
hydrogen sensing performance of electrospun $\mathrm{SnO}_{2}$ nanofibers [112]. Among them, the Al doping would generate more oxygen vacancies through the $\mathrm{SnO}_{2}$ crystals due to the partial substitution of $\mathrm{Sn}^{4+}$ cations with lower valence $\mathrm{Al}^{3+}$ cations together with their different ions radius. As increasing the doping concentration, external heterojunctions will be formed between $\mathrm{Al}_{2} \mathrm{O}_{3}$ and $\mathrm{SnO}_{2}$ owing to the expulsion of $\mathrm{Al}^{3+}$ ions from the $\mathrm{SnO}_{2}$ crystals. The $\mathrm{Al}_{2} \mathrm{O}_{3}$ nanoclusters could act as catalytic sites with spill over effect for redox processes and oxygen dissociation, which result in the enhanced sensing performance, however, the $\mathrm{Al}_{2} \mathrm{O}_{3}$ nanoclusters will reduce the surface area and amount of oxygen vacancies. The same authors also reported improved hydrogen monitoring properties based on $\mathrm{p}-\mathrm{NiO} / \mathrm{n}-\mathrm{SnO}_{2}$ heterojunction composite nanofibers [115]. By adding $\mathrm{NiO}, p-n$ heterojunction is formed at the interface between $\mathrm{NiO}$ and $\mathrm{SnO}_{2}$. In this case, in an oxidizing atmosphere a thicker charge depletion layer is formed near the grain surface of $\mathrm{SnO}_{2}$ as a $p$ - $n$ junction. Therefore, a larger resistance change will obtained when the sensor was exposed to hydrogen containing atmosphere, which resulted in the higher sensitivity of the $\mathrm{p}-\mathrm{NiO} / \mathrm{n}-\mathrm{SnO}_{2}$ heterojunction composite nanofibers than the pure $\mathrm{SnO}_{2}$ nanofibers.

Figure 13. Schematic illustration of the ceramic-tube gas sensor with nanofibers coating on the surface (reprinted from [112] with permission from Elsevier).

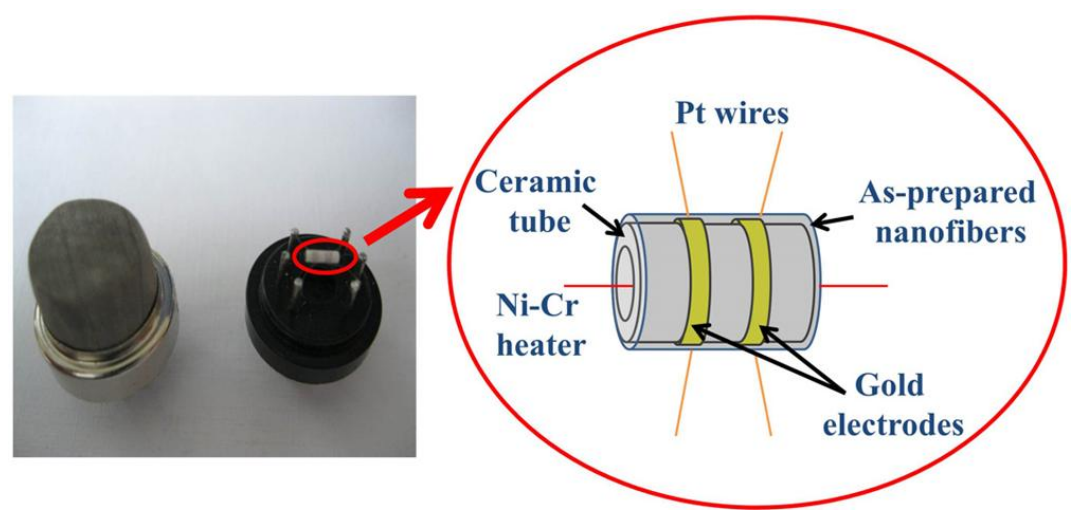

Lee and co-workers have demonstrated an ultra-sensitive hydrogen sensor based on Pd-decorated $\mathrm{SnO}_{2}$ NWs, which can be operated under RT with the assistance of the "spill-over effect" induced by Pd nanoparticles.[17] The sensors showed ultra-high sensitivity $\left(1.2 \times 10^{3}, S=\Delta R / R_{\mathrm{g}}\right)$ and fast response time $(<2 \mathrm{~s})$ upon exposure to $10,000 \mathrm{ppm} \mathrm{H}_{2}$ at $\mathrm{RT}$. These sensors were also found to enable a significant electrical conductance modulation upon exposure to extremely low concentrations (40 ppm) of $\mathrm{H}_{2}$ in the air.

Heterostructures of SMO 1D nanostructures have been used for improving hydrogen sensing properties due to their high surface area and hybrid properties. Singh et al. have synthesized $\mathrm{In}_{2} \mathrm{O}_{3}-\mathrm{ZnO}$ core-shell NWs by a two-step growth process, with polycrystalline $\mathrm{ZnO}$ coating on the single crystalline $\mathrm{In}_{2} \mathrm{O}_{3}$ NWs (shown in Figure 14) [116]. $\mathrm{In}_{2} \mathrm{O}_{3}-\mathrm{ZnO}$ core-shell NW networks showed higher response to reducing gases such as $\mathrm{H}_{2}, \mathrm{CO}$, or ethanol compared to oxidizing gases such as $\mathrm{NO}_{2}$. Comparing with the $\mathrm{In}_{2} \mathrm{O}_{3} \mathrm{NW}$ networks with only homointerfaces at the junctions, the $\mathrm{In}_{2} \mathrm{O}_{3}-\mathrm{ZnO}$ core-shell NW networks formed both homo- and hetero-junctions at the interfaces. The energy barrier induced by the homojunctions between $\mathrm{In}_{2} \mathrm{O}_{3} \mathrm{NWs}$ has a profound effect on the gas sensing performance, which was also mentioned above. Moreover, the heterojunctions of $\operatorname{In}_{2} \mathrm{O}_{3}$ and $\mathrm{ZnO}$ lead to additional electron depletion layers due to the difference in work function. As the charge carriers 
need to travel through the interconnected NWs, the homojunction between two interconnected NWs, the grain boundaries in polycrystalline $\mathrm{ZnO}$ shell layer and the heterojucntion between $\operatorname{In}_{2} \mathrm{O}_{3}$ and $\mathrm{ZnO}$ must be passed through. When the sensor was exposed to hydrogen gases (or other reducing gases), all potential barriers were modulated, which may be the reason for explaining the higher sensing performance than $\mathrm{In}_{2} \mathrm{O}_{3} \mathrm{NW}$ networks.

Figure 14. The TEM analysis of $\mathrm{In}_{2} \mathrm{O}_{3}-\mathrm{ZnO}$ core shell NW. (a) low magnifying TEM image; (b) HRTEM image; (c) SAED pattern obtained from the shell; (d) SAED pattern obtained from the core; (e) line profile obtained by TEM-EDS analysis (reprinted from [116] with permission from Elsevier).

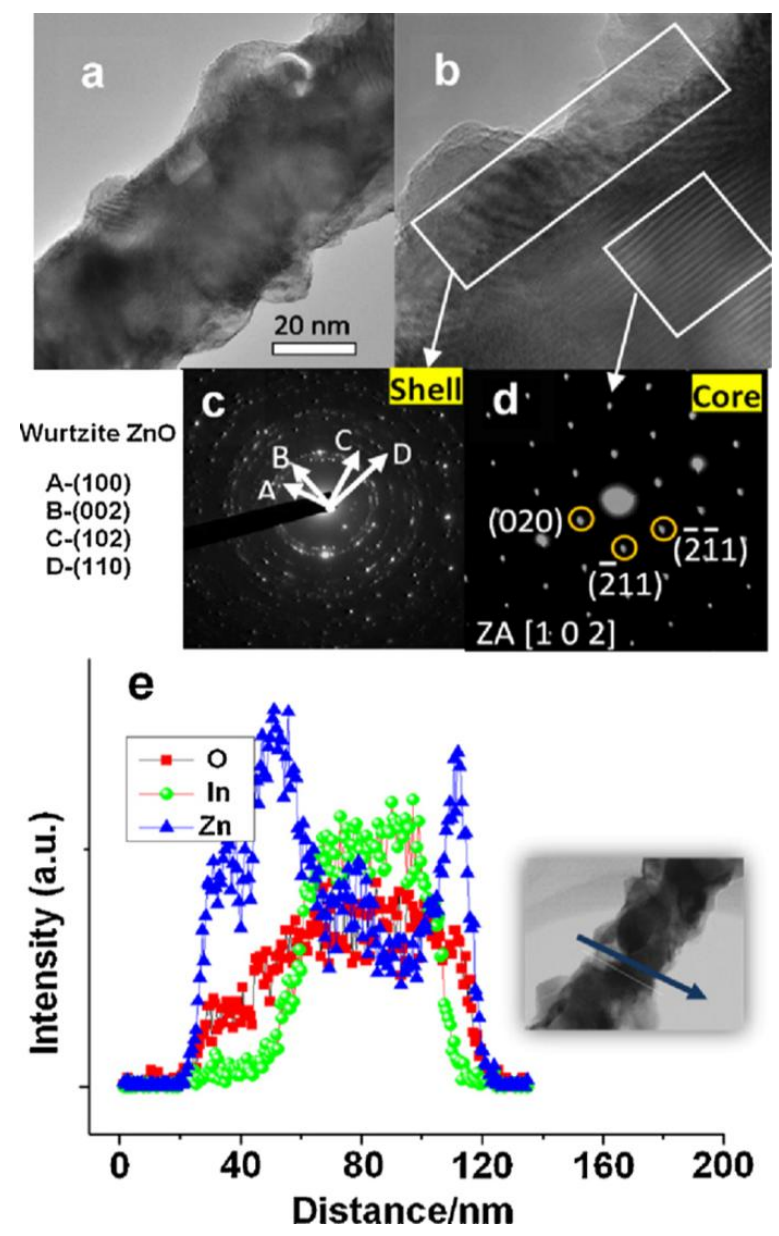

1D SMO nanostructure arrays, which are so-called quasi-1D nanostructures were also employed as hydrogen sensing materials due to their high specific surface area. Senik et al. have reported anodic oxidized highly-oriented $\mathrm{TiO}_{2}$ nanotubes for a hydrogen sensor, which exhibited high hydrogen sensitivity at RT but with a slow response time [10]. Jho and co-workers fabricated a hydrogen gas sensor by employing vertically aligned anatase $\mathrm{TiO}_{2}$ nanotube arrays prepared by AAO template-assisted atomic layer deposition method [12]. As shown in Figure 15, the sensor exhibited outstanding hydrogen sensing performance at low temperature (around $100{ }^{\circ} \mathrm{C}$ ) in air environment with a maximum gas response $\left(S=R_{0} / R_{\mathrm{g}}\right)$ of 100.5 to $1,000 \mathrm{ppm}$ hydrogen, as well as great stability, repeatability and selectivity against several reducing gases including $\mathrm{NH}_{3}, \mathrm{CO}$, and $\mathrm{C}_{2} \mathrm{H}_{5} \mathrm{OH}$. Moreover, the response time was extremely short $(<1 \mathrm{~s})$ even in the low temperature range. They attributed the 
outstanding performance to the vertically aligned $\mathrm{TiO}_{2}$ nanotubes locating apart from each other, which presumably resulted in the rapid gas diffusion in-between the nanotubes, and consequently allowed the hydrogen gas to quickly reach the entire surface of the nanotube. Besides, the hydrogen sensing properties of ZnO nanopillar and NR arrays have also been investigated [117,118].

There are some novel types of hydrogen sensors based on SMO 1D nanostructures which possess novel functions or device architectures compared with the NW-based sensors mentioned above. For instance, Liu et al. fabricated aligned $\mathrm{ZnO}$ nanotubes by electrospinning and sputtering techniques [119].

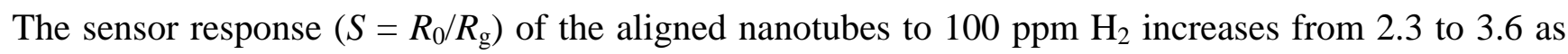
the temperature increases from 200 to $400{ }^{\circ} \mathrm{C}$. Beside, the sensor response of the $\mathrm{ZnO}$ nanotubes increases compared with that of the $\mathrm{ZnO}$ film prepared under the same condition. Zhu and co-workers have demonstrated the self-heated hydrogen sensor based on Pt-coated $\mathrm{W}_{18} \mathrm{O}_{49} \mathrm{NW}$ networks with high sensitivity, good selectivity and low power consumption [120]. The hydrogen response obtained for the same concentration of hydrogen increases with increasing the applied voltage on the Pt-coated $\mathrm{W}_{18} \mathrm{O}_{49} \mathrm{NW}$ network due to the increased self-heating of NWs, which lead to the increase of surface reactivity for redox reactions between adsorbed oxygen species and hydrogen atoms spilled over by Pt.

Figure 15. The SEM image (a,b) and hydrogen sensing performance (c) of vertically aligned anatase $\mathrm{TiO}_{2}$ nanotube arrays (reprinted from [12] with permission from Elsevier).

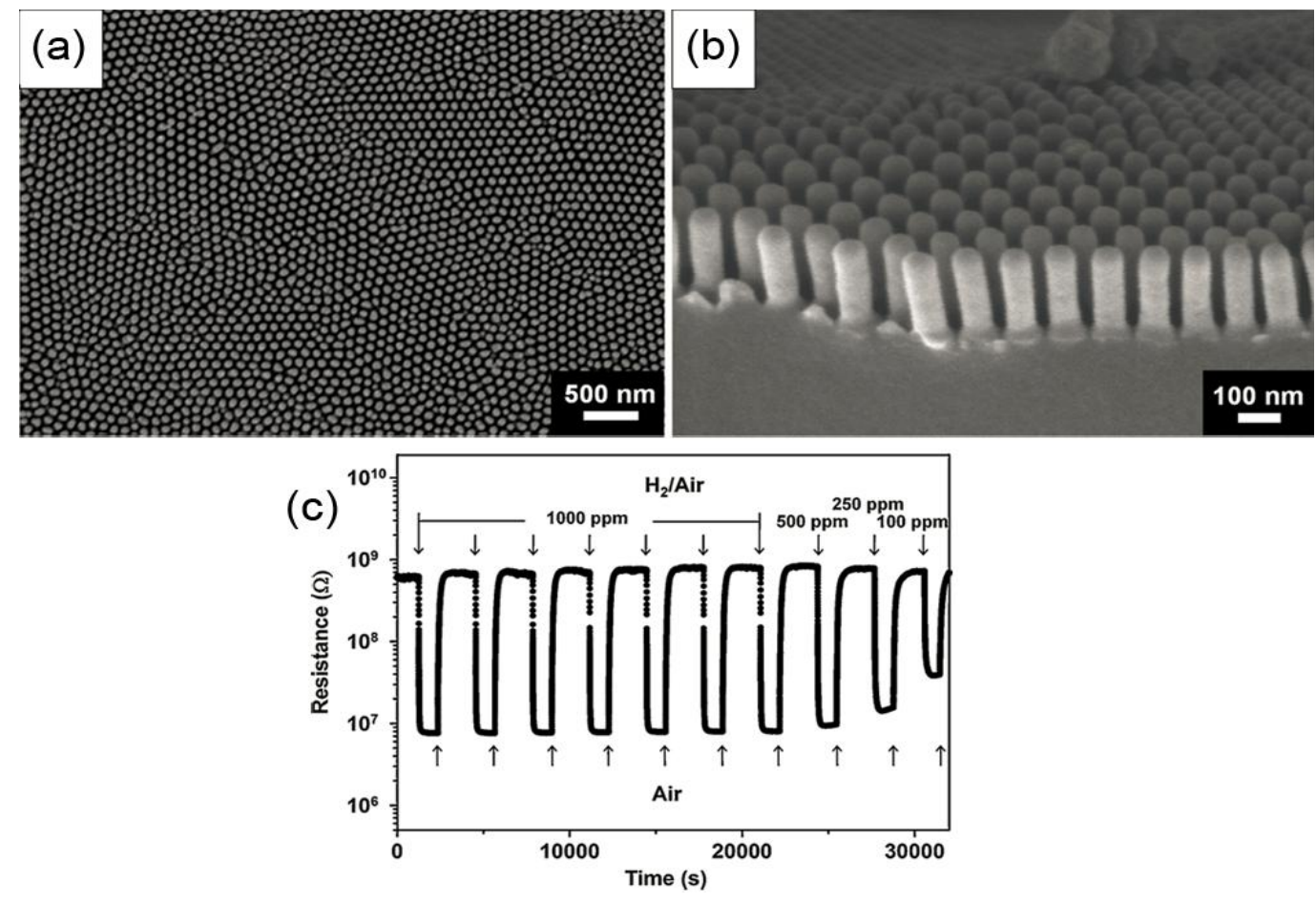

Recently, Tonezzer and Lacerda have reported a novel ZnO NW architecture integrated on a carbon microfiber textile [121]. Fast and sensitive hydrogen response was observed with an optimum response of 11 and response/recovery time of less than $12 \mathrm{~s}$ at $280{ }^{\circ} \mathrm{C}$. Furthermore, the LOD is down to $4 \mathrm{ppm}$ of hydrogen gas. Similar ZnO NRs fabrics were also reported by Lim and co-workers [122]. The fabric's response $\left(S=\Delta R / R_{0}\right)$ after $10 \mathrm{~min}$ exposure of $1,000 \mathrm{ppm} \mathrm{H}_{2}$ gas was $\sim 83 \%$ after Pt-decoration compared to $27 \%$ without Pt catalyst. Both of the two novel structures give rise to higher surface area and flexibility of the device, but limit the application under high-temperature conditions. 
Moreover, the fact that lithographic techniques are not needed allows for large-scale and low-cost fabrication of gas sensors, as well as their application in the smart textile field.

\section{Summary}

In this article, we provide a comprehensive review of the hydrogen sensing properties of SMO nanostructures, including thin films and 1D nanostructures. According to their sensing behavior, the SMO sensors can be divided into resistance, Schottky diode, MOSFET, MOS capacitor, optical and acoustic types. Some critical issues such as sensitivity, response time, recovery time, gas selectivity, limit of detection (LOD), temperature/humidity influence and long-term stability were discussed. Nanostructured SMO thin film hydrogen sensors have the advantages of simple fabrication processes, good compatibility with integrated circuits for building integrated sensors, high sensitivity and short response/recovery times, etc. However, most thin film sensors still need to work at elevated temperatures, which results in poor long-term stability and high power consumption. The influences of grain size, porosity, orientation, doping and surface decoration as well as the device architecture on the sensing performance of hydrogen sensors have been widely investigated for improving gas selectivity and hydrogen response at low temperatures. Hydrogen sensors based on individual SMO 1D nanostructures can be obtained by employing nano-scale fabrication by FIB or EBL techniques, and the products exhibited ultra-sensitive, fast and highly selective responses to low concentration of hydrogen gas at RT, as well as outstanding long-term stability. Multiple SMO 1D nanostructures such as NW network-based hydrogen sensors fabricated by scalable micro-fabrication techniques were more suitable for practical applications than individual NWs. Interdigitated electrodes were always used for fabricating sensors based on single crystalline NWs, while ceramic tubes with a pair of Au electrodes were always used for fabricating sensors based on polycrystalline nanofibers. Doping, and noble metal decoration were also used for improving the sensing performance, while the effect of nanojunctions, heterostructures such as core-shell NWs were also investigated. Although a lot of efforts have been done for promoting the practical application of SMO nanostructure-based hydrogen sensors, there are some critical issues which still need to be resolved, e.g., the standard definition of sensor parameters and testing method, the investigation of standard LOD, long-term stabilities, as well as the validity, repeatability and calibration of the sensors.

\section{Acknowledgments}

This work was supported by the National Science Foundation of China (Grant No. 90923013, 51173038, 50902046), Specialized Research Fund for the Doctoral Program of Higher Education (Grant No. 20114208130001), the International Cooperation project of Wuhan City, PR China (Grant No. 201070934340) and the Youth Chenguang Project of Science and Technology of Wuhan City, China (Grant No. 201150431133).

\section{References}

1. Hübert, T.; Boon-Brett, L.; Black, G.; Banach, U. Hydrogen sensors-A review. Sens. Actuat. B 2011, 157, 329-352. 
2. Buttner, W.J.; Post, M.B.; Burgess, R.; Rivkin, C. An overview of hydrogen safety sensors and requirements. Int. J. Hydrog. Energy 2011, 36, 2462-2470.

3. Aroutiounian, V. Hydrogen detectors. Int. Sci. J. Altern. Energy Ecol. 2005, 3, 21-31.

4. Wright, J.S.; Lim, W.; Norton, D.P.; Pearton, S.J.; Ren, F.; Johnson, J.L.; Ural, A. Nitride and oxide semiconductor nanostructured hydrogen gas sensors. Semicond. Sci. Technol. 2010, doi: 10.1088/0268-1242/25/2/024002.

5. Wang, C.; Yin, L.; Zhang, L.; Xiang, D.; Gao, R. Metal oxide gas sensors: Sensitivity and influencing factors. Sensors 2010, 10, 2088-2106.

6. Potje-Kamloth, K. Semiconductor junction gas sensors. Chem. Rev. 2008, 108, 367-399.

7. Barsan, N.; Koziej, D.; Weimar, U. Metal oxide-based gas sensor research: How to? Sens. Actuat. B 2007, 121, 18-35.

8. Shimizu, Y.; Kuwano, N.; Hyodo, T.; Egashira, M. High $\mathrm{H}_{2}$ sensing performance of anodically oxidized $\mathrm{TiO}_{2}$ film contacted with Pd. Sens. Actuat. B 2002, 83, 195-201.

9. Shimizu, Y.; Hyodo, T.; Egashira, M. $\mathrm{H}_{2}$ sensing performance of anodically oxidized $\mathrm{TiO}_{2}$ thin films equipped with Pd electrode. Sens. Actuat. B 2007, 121, 219-230.

10. Şennik, E.; Çolak, Z.; Kılınç, N.; Öztürk, Z.Z. Synthesis of highly-ordered $\mathrm{TiO}_{2}$ nanotubes for a hydrogen sensor. Int. J. Hydrog. Energy 2010, 35, 4420-4427.

11. Lu, C.; Chen, Z. High-temperature resistive hydrogen sensor based on thin nanoporous rutile $\mathrm{TiO}_{2}$ film on anodic aluminum oxide. Sens. Actuat. B 2009, 140, 109-115.

12. Lee, J.; Kim, D.H.; Hong, S.-H.; Jho, J.Y. A hydrogen gas sensor employing vertically aligned $\mathrm{TiO}_{2}$ nanotube arrays prepared by template-assisted method. Sens. Actuat. B 2011, 160, 1494-1498.

13. Iwanaga, T.; Hyodo, T.; Shimizu, Y.; Egashira, M. $\mathrm{H}_{2}$ sensing properties and mechanism of anodically oxidized $\mathrm{TiO}_{2}$ film contacted with Pd electrode. Sens. Actuat. B 2003, 93, 519-525.

14. Hyodo, T.; Ohoka, J.; Shimizu, Y.; Egashira, M. Design of anodically oxidized $\mathrm{Nb}_{2} \mathrm{O}_{5}$ films as a diode-type $\mathrm{H}_{2}$ sensing material. Sens. Actuat. B 2006, 117, 359-366.

15. Huang, J.; Wan, Q. Gas sensors based on semiconducting metal oxide one-dimensional nanostructures. Sensors 2009, 9, 9903-9924.

16. Choi, K.J.; Jang, H.W. One-dimensional oxide nanostructures as gas-sensing materials: Review and issues. Sensors 2010, 10, 4083-4099.

17. Lee, J.M.; Park, J.-E.; Kim, S.; Kim, S.; Lee, E.; Kim, S.-J.; Lee, W. Ultra-sensitive hydrogen gas sensors based on Pd-decorated tin dioxide nanostructures: Room temperature operating sensors. Int. J. Hydrog. Energy 2010, 35, 12568-12573.

18. Kumar, M.K.; Tan, L.K.; Gosvami, N.N.; Gao, H. Conduction-atomic force microscopy study of $\mathrm{H}_{2}$ sensing mechanism in $\mathrm{Pd}$ nanoparticles decorated $\mathrm{TiO}_{2}$ nanofilm. J. Appl. Phys. 2009, 106, 044308:1-044308:5.

19. Wagner, C. The mechanism of the decomposition of nitrous oxide on zinc oxide as catalyst. J. Chem. Phys. 1950, 18, 69-71.

20. Seiyama, T.; Kato, A.; Fujiishi, K.; Nagatani, M. A new detector for gaseous components using semiconductive thin films. Anal. Chem. 1962, 34, 1502-1503.

21. Law, M.; Kind, H.; Messer, B.; Kim, F.; Yang, P. Photochemical sensing of $\mathrm{NO}_{2}$ with $\mathrm{SnO}_{2}$ nanoribbon nanosensors at room temperature. Angew. Chem. 2002, 114, 2511-2514.

22. Comini, E.; Faglia, G.; Sberveglieri, G.; Pan, Z.; Wang, Z.L. Stable and highly sensitive gas sensors based on semiconducting oxide nanobelts. Appl. Phys. Lett. 2002, 81, 1869-1871. 
23. Wang, C.; Zhou, G.; Li, J.; Yan, B.; Duan, W. Hydrogen-induced metallization of zinc oxide ( $2 \overline{1} \overline{1} 0$ ) surface and nanowires: The effect of curvature. Phys. Rev. B 2008, 77, 245303:1-245303:7.

24. Xu, H.; Fan, W.; Rosa, A.L.; Zhang, R.Q.; Frauenheim, T. Hydrogen and oxygen adsorption on ZnO nanowires: A first-principles study. Phys. Rev. B 2009, 79, 073402.

25. Raupp, G.B.; Dumesic, J.A. Adsorption of carbon monoxide, carbon dioxide, hydrogen, and water on titania surfaces with different oxidation states. J. Phys. Chem. 1985, 89, 5240-5246.

26. Varghese, O.K.; Gong, D.; Paulose, M.; Ong, K.G.; Grimes, C.A. Hydrogen sensing using titania nanotubes. Sens. Actuat. B 2003, 93, 338-344.

27. Yamamoto, N.; Tonomura, S.; Matsuoka, T.; Tsubomura, H. A study on a palladium-titanium oxide Schottky diode as a detector for gaseous components. Surf. Sci. 1980, 92, 400-406.

28. Keramati, B.; Zemel, J.N. Pd-thin-SiO $2-\mathrm{Si}$ diode. I. Isothermal variation of $\mathrm{H}_{2}$-induced interfacial trapping states. J. Appl. Phys. 1982, 53, 1091-1099.

29. Lu, C.; Chen, Z.; Singh, V. Highly hydrogen-sensitive $\mathrm{SnO}_{2}$ nanoscale-particle films with platinum electrodes. Sens. Actuat. B 2010, 146, 145-153.

30. Miyazaki, H.; Hyodo, T.; Shimizu, Y.; Egashira, M. Hydrogen-sensing properties of anodically oxidized $\mathrm{TiO}_{2}$ film sensors: Effects of preparation and pretreatment conditions. Sens. Actuat. B 2005, 108, 467-472.

31. Das, S.N.; Kar, J.P.; Choi, J.-H.; Lee, T.I.; Moon, K.-J.; Myoung, J.-M. Fabrication and characterization of $\mathrm{ZnO}$ single nanowire-based hydrogen sensor. J. Phys. Chem. C 2010, 114, 1689-1693.

32. Kim, S.; Kang, B.S.; Ren, F.; Ip, K.; Heo, Y.W.; Norton, D.P.; Pearton, S.J. Sensitivity of $\mathrm{Pt} / \mathrm{ZnO}$ Schottky diode characteristics to hydrogen. Appl. Phys. Lett. 2004, 84, 1698-1700.

33. Shafiei, M.; Yu, J.; Arsat, R.; Kalantar-Zadeh, K.; Comini, E.; Ferroni, M.; Sberveglieri, G.; Wlodarski, W. Reversed bias Pt/nanostructured ZnO Schottky diode with enhanced electric field for hydrogen sensing. Sens. Actuat. B 2010, 146, 507-512.

34. Mishra, V.N.; Agarwal, R.P. Sensitivity, response and recovery time of $\mathrm{SnO}_{2}$ based thick-film sensor array for $\mathrm{H}_{2}, \mathrm{CO}, \mathrm{CH}_{4}$ and LPG. Microelectron. J. 1998, 29, 861-874.

35. Gaman, V. Basic physics of semiconductor hydrogen sensors. Russ. Phys. J. 2008, 51, 425-441.

36. Shafiei, M.; Kalantar-Zadeh, K.; Wlodarski, W.; Comini, E.; Ferroni, M.; Sberveglieri, G.; Kaciulis, S.; Pandolfi, L. Hydrogen gas sensing performance of $\mathrm{Pt} / \mathrm{SnO}_{2}$ Nanowires/SiC MOS Devices. Int. J. Smart Sens. Intell. Syst. 2008, 1, 771-783.

37. Anderson, T.; Ren, F.; Pearton, S.; Kang, B.S.; Wang, H.-T.; Chang, C.-Y.; Lin, J. Advances in hydrogen, carbon dioxide, and hydrocarbon gas sensor technology using $\mathrm{GaN}$ and ZnO-based devices. Sensors 2009, 9, 4669-4694.

38. Chen, X.F.; Zhu, W.G.; Tan, O.K. Microstructure, dielectric properties and hydrogen gas sensitivity of sputtered amorphous $\mathrm{Ba}_{0.67} \mathrm{Sr}_{0.33} \mathrm{TiO}_{3}$ thin films. Mater. Sci. Eng. B 2000, 77, 177-184.

39. Deng, J.; Zhu, W.; Tan, O.K.; Yao, X. Amorphous $\mathrm{Pb}(\mathrm{Zr}, \mathrm{Ti}) \mathrm{O}_{3}$ thin film hydrogen gas sensor. Sens. Actuat. B 2001, 77, 416-420. 
40. Tan, O.K.; Zhu, W.; Tse, M.S.; Yao, X. Hydrogen-sensitive I-V characteristics of metal-ferroelectric gas sensor device fabricated by sol-gel technique. Mater. Sci. Eng. B 1999, $58,221-228$.

41. Tan, O.K.; Chen, X.F.; Zhu, W. Amorphous ferroelectric thin film capacitive device for hydrogen detection. J. Mater. Sci. 2003, 38, 4353-4363.

42. Nakagomi, S.; Wingqvist, G.; Åbom, A.E.; Helmersson, U.; Spetz, A.L. Hydrogen sensing by NKN thin film with high dielectric constant and ferroelectric property. Sens. Actuat. B 2005, 108, 490-495.

43. Steele, M.C.; Hile, J.W.; MacIver, B.A. Hydrogen-sensitive palladium gate MOS capacitors. J. Appl. Phys. 1976, 47, 2537-2538.

44. Kang, W.P.; Kim, C.K. Performance and detection mechanism of a new class of catalyst (Pd, Pt, or $\mathrm{Ag})$-adsorptive oxide $\left(\mathrm{SnO}_{\mathrm{x}}\right.$ or $\left.\mathrm{ZnO}\right)$-insulator-semiconductor gas sensors. Sens. Actuat. B 1994, 22, 47-55.

45. Yadava, L.; Dwivedi, R.; Srivastava, S.K. A titanium dioxide-based MOS hydrogen sensor. Solid State Electon. 1990, 33, 1229-1234.

46. Yadav, L.; Chandragupta, N.; Dwivedi, R.; Singh, R. Sensing behavior and mechanism of titanium dioxide-based MOS hydrogen sensor. Microelectron. J. 2007, 38, 1226-1232.

47. Weng, M.H.; Mahapatra, R.; Horsfall, A.B.; Wright, N.G. Trap-assisted gas sensing mechanism in $\mathrm{Pd} / \mathrm{TiO}_{2} / \mathrm{SiO}_{2} / \mathrm{SiC}$ capacitors at high temperatures. IEEE Sens. J. 2007, 7, 1395-1399.

48. Stiblert, L.; Svensson, C. Hydrogen leak detector using a Pd-gate MOS transistor. Rev. Sci. Instrum. 1975, 46, 1206-1208.

49. Lundstrom, I.; Shivaraman, S.; Svensson, C.; Lundkvist, L. A hydrogen-sensitive MOS field-effect transistor. Appl. Phys. Lett. 1975, 26, 55-57.

50. Zeng, Z.M.; Wang, K.; Zhang, Z.X.; Chen, J.J.; Zhou, W.L. The detection of $\mathrm{H}_{2} \mathrm{~S}$ at room temperature by using individual indium oxide nanowire transistors. Nanotechnology 2009, doi: 10.1088/0957-4484/20/4/045503.

51. Zhang, D.; Li, C.; Liu, X.; Han, S.; Tang, T.; Zhou, C. Doping dependent $\mathrm{NH}_{3}$ sensing of indium oxide nanowires. Appl. Phys. Lett. 2003, 83, 1845-1847.

52. Andrei, P.; Fields, L.L.; Zheng, J.P.; Cheng, Y.; Xiong, P. Modeling and simulation of single nanobelt $\mathrm{SnO}_{2}$ gas sensors with FET structure. Sens. Actuat. B 2007, 128, 226-234.

53. Masanori, A. Recent advances in optochemical sensors for the detection of $\mathrm{H}_{2}, \mathrm{O}_{2}, \mathrm{O}_{3}, \mathrm{CO}, \mathrm{CO}_{2}$ and $\mathrm{H}_{2} \mathrm{O}$ in air. TrAC Trends Anal. Chem. 2006, 25, 937-948.

54. Sekimoto, S.; Nakagawa, H.; Okazaki, S.; Fukuda, K.; Asakura, S.; Shigemori, T.; Takahashi, S. A fiber-optic evanescent-wave hydrogen gas sensor using palladium-supported tungsten oxide. Sens. Actuat. B 2000, 66, 142-145.

55. Jakubik, W.P.; Urbańczyk, M.W.; Kochowski, S.; Bodzenta, J. Bilayer structure for hydrogen detection in a surface acoustic wave sensor system. Sens. Actuat. B 2002, 82, 265-271.

56. Huang, F.C.; Chen, Y.Y.; Wu, T.T. A room temperature surface acoustic wave hydrogen sensor with Pt coated ZnO nanorods. Nanotechnology 2009, doi: 10.1088/0957-4484/20/6/065501.

57. Fechete, A.C.; Wlodarski, W.; Kalantar-Zadeh, K.; Holland, A.S.; Antoszewski, J.; Kaciulis, S.; Pandolfi, L. SAW-based gas sensors with rf sputtered $\mathrm{InO}_{\mathrm{x}}$ and PECVD SiNx films: Response to $\mathrm{H}_{2}$ and $\mathrm{O}_{3}$ gases. Sens. Actuat. B 2006, 118, 362-367. 
58. Xiong, J.; Gu, H.-S.; Hu, K.; Hu, M.-Z. Fabrication and frequency response characteristics of AlN-based solidly mounted resonator. Chin. Phys. Lett. 2009, doi: 10.1088/0256-307X/26/4/048104.

59. Hieda, K.; Hyodo, T.; Shimizu, Y.; Egashira, M. Preparation of porous tin dioxide powder by ultrasonic spray pyrolysis and their application to sensor materials. Sens. Actuat. B 2008, 133, 144-150.

60. Shen, Y.; Yamazaki, T.; Liu, Z.; Meng, D.; Kikuta, T. Hydrogen sensing properties of Pd-doped $\mathrm{SnO}_{2}$ sputtered films with columnar nanostructures. Thin Solid Films 2009, 517, 6119-6123.

61. Gong, J.; Chen, Q.; Lian, M.-R.; Liu, N.-C.; Stevenson, R.G.; Adami, F. Micromachined nanocrystalline silver doped $\mathrm{SnO}_{2} \mathrm{H} 2 \mathrm{~S}$ sensor. Sens. Actuat. B 2006, 114, 32-39.

62. Qi, Q.; Zhang, T.; Zheng, X.; Fan, H.; Liu, L.; Wang, R.; Zeng, Y. Electrical response of $\mathrm{Sm}_{2} \mathrm{O}_{3}$-doped $\mathrm{SnO}_{2}$ to $\mathrm{C}_{2} \mathrm{H}_{2}$ and effect of humidity interference. Sens. Actuat. B 2008, 134, 36-42.

63. Sysoev, V.V.; Schneider, T.; Goschnick, J.; Kiselev, I.; Habicht, W.; Hahn, H.; Strelcov, E.; Kolmakov, A. Percolating $\mathrm{SnO}_{2}$ nanowire network as a stable gas sensor: Direct comparison of long-term performance versus $\mathrm{SnO}_{2}$ nanoparticle films. Sens. Actuat. B 2009, 139, 699-703.

64. Hernandez-Ramirez, F.; Prades, J.D.; Jimenez-Diaz, R.; Fischer, T.; Romano-Rodriguez, A.; Mathur, S.; Morante, J.R. On the role of individual metal oxide nanowires in the scaling down of chemical sensors. Phys. Chem. Chem. Phys. 2009, 11, 7105-7110.

65. Adamyan, A.; Adamyan, Z.; Aroutiounian, V.; Arakelyan, A.; Touryan, K.; Turner, J. Sol-gel derived thin-film semiconductor hydrogen gas sensor. Int. J. Hydrog. Energy 2007, 32, 4101-4108.

66. Adamyan, A.Z.; Adamyan, Z.N.; Aroutiounian, V.M. Study of sensitivity and response kinetics changes for $\mathrm{SnO}_{2}$ thin-film hydrogen sensors. Int. J. Hydrog. Energy 2009, 34, 8438-8443.

67. Sadek, A.Z.; Partridge, J.G.; McCulloch, D.G.; Li, Y.X.; Yu, X.F.; Wlodarski, W.; Kalantar-zadeh, K. Nanoporous $\mathrm{TiO}_{2}$ thin film based conductometric $\mathrm{H}_{2}$ sensor. Thin Solid Films 2009, 518, 1294-1298.

68. Hung, N.L.; Ahn, E.; Park, S.; Jung, H.; Kim, H.; Hong, S.-K.; Kim, D.; Hwang, C. Synthesis and hydrogen gas sensing properties of $\mathrm{ZnO}$ wirelike thin films. J. Vaccum Sci. Technol. A 2009, 27, 1347:1-1347:5.

69. Wang, Z.; Hu, Y.; Wang, W.; Zhang, X.; Wang, B.; Tian, H.; Wang, Y.; Guan, J.; Gu, H. Fast and highly-sensitive hydrogen sensing of $\mathrm{Nb}_{2} \mathrm{O}_{5}$ nanowires at room temperature. Int. J. Hydrog. Energy 2012, 37, 4526-4532.

70. Choi, Y.-H.; Hong, S.-H. $\mathrm{H}_{2}$ sensing properties in highly oriented $\mathrm{SnO}_{2}$ thin films. Sens. Actuat. $B$ 2007, 125, 504-509.

71. Ren, F.; Huang, L.; Ling, Y.; Feng, J. Grain boundaries dependent hydrogen sensitivity in MAO-TiO 2 thin films sensors. Sens. Actuat. B 2010, 148, 195-199.

72. Hoa, N.D.; An, S.Y.; Dung, N.Q.; Van Quy, N.; Kim, D. Synthesis of p-type semiconducting cupric oxide thin films and their application to hydrogen detection. Sens. Actuat. B 2010, 146, 239-244.

73. Wu, D.; Zhang, Q.; Tao, M. LSDA+U study of cupric oxide: Electronic structure and native point defects. Phys. Rev. B 2006, 73, 235206:1-235206:6.

74. Steinebach, H.; Kannan, S.; Rieth, L.; Solzbacher, F. $\mathrm{H}_{2}$ gas sensor performance of $\mathrm{NiO}$ at high temperatures in gas mixtures. Sens. Actuat. B 2010, 151, 162-168. 
75. Kobrinsky, V.; Fradkin, E.; Lumelsky, V.; Rothschild, A.; Komem, Y.; Lifshitz, Y. Tunable gas sensing properties of p- and n-doped ZnO thin films. Sens. Actuat. B 2010, 148, 379-387.

76. Galstyan, V.E.; Aroutiounian, V.M.; Arakelyan, V.M.; Shahnazaryan, G.E. Investigation of hydrogen sensor made of $\mathrm{ZnO}<\mathrm{Al}>$ thin film. Armen. J. Phys. 2009, 1, 242-246.

77. Liu, Y.; Hang, T.; Xie, Y.; Bao, Z.; Song, J.; Zhang, H.; Xie, E. Effect of Mg doping on the hydrogen-sensing characteristics of $\mathrm{ZnO}$ thin films. Sens. Actuat. B 2011, 160, 266-270.

78. Fardindoost, S.; Iraji Zad, A.; Rahimi, F.; Ghasempour, R. Pd doped $\mathrm{WO}_{3}$ films prepared by sol-gel process for hydrogen sensing. Int. J. Hydrog. Energy 2010, 35, 854-860.

79. Fasaki, I.; Suchea, M.; Mousdis, G.; Kiriakidis, G.; Kompitsas, M. The effect of Au and Pt nanoclusters on the structural and hydrogen sensing properties of $\mathrm{SnO}_{2}$ thin films. Thin Solid Films 2009, 518, 1109-1113.

80. Gong, J.; Sun, J.; Chen, Q. Micromachined sol-gel carbon nanotube/ $\mathrm{SnO}_{2}$ nanocomposite hydrogen sensor. Sens. Actuat. B 2008, 130, 829-835.

81. Wongchoosuk, C.; Wisitsoraat, A.; Phokharatkul, D.; Tuantranont, A.; Kerdcharoen, T. Multi-walled carbon nanotube-doped tungsten oxide thin films for hydrogen gas sensing. Sensors 2010, 10, 7705-7715.

82. Deshpande, S.; Seal, S.; Zhang, P.; Cho, H.J.; Posey, N. Electrode architecture in tuning room temperature sensing kinetics of nanomicrointegrated hydrogen sensor. Appl. Phys. Lett. 2007, 90, 073118:1-073118:3.

83. Shukla, S.; Zhang, P.; Cho, H.J.; Seal, S.; Ludwig, L. Room temperature hydrogen response kinetics of nano-micro-integrated doped tin oxide sensor. Sens. Actuat. B 2007, 120, 573-583.

84. Shukla, S.; Zhang, P.; Cho, H.; Ludwig, L.; Seal, S. Significance of electrode-spacing in hydrogen detection for tin oxide-based MEMS sensor. Int. J. Hydrog. Energy 2008, 33, 470-475.

85. Yu, J.; Ippolito, S.J.; Wlodarski, W.; Strano, M.; Kalantar-Zadeh, K. Nanorod based Schottky contact gas sensors in reversed bias condition. Nanotechnology 2010, doi: 10.1088/0957-4484/ 21/26/265502.

86. Yu, J.; Shafiei, M.; Breedon, M.; Kalantar-zadeh, K.; Wlodarski, W. A comparison of forward and reverse bias operation in a $\mathrm{Pt} /$ nanostructured $\mathrm{ZnO}$ Schottky diode based hydrogen sensor. Procedia Chem. 2009, 1, 979-982.

87. Phan, D.-T.; Chung, G.-S. Surface acoustic wave hydrogen sensors based on ZnO nanoparticles incorporated with a Pt catalyst. Sens. Actuat. B 2011, doi: 10.1016/j.snb.2011.10.042.

88. Yan, Q.; Tao, S.; Toghiani, H. Optical fiber evanescent wave absorption spectrometry of nanocrystalline tin oxide thin films for selective hydrogen sensing in high temperature gas samples. Talanta 2009, 77, 953-961.

89. Yang, M.; Liu, H.; Zhang, D.; Tong, X. Hydrogen sensing performance comparison of Pd layer and $\mathrm{Pd} / \mathrm{WO}_{3}$ composite thin film coated on side-polished single- and multimode fibers. Sens. Actuat. B 2010, 149, 161-164.

90. Xu, X.J.; Fang, X.S.; Bando, Y.; Zhai, T.Y.; Zeng, H.B.; Liu, B.D.; Hu, X.Y.; Golberg, D. Tube-in-tube $\mathrm{TiO}_{2}$ nanotubes with porous walls: Fabrication, formation mechanism and photocatalytic properties. Small 2011, 7, 445-449. 
91. Zeng, H.B.; Xu, X.J.; Bando, Y.; Gautam, U.K.; Zhai, T.Y.; Fang, X.S.; Liu, B.D.; Golberg, D. Template deformation-tailored zno nanorod/nanowire arrays: Full growth control and optimization of field-emission. Adv. Funct. Mater. 2009, 19, 3165-3172.

92. Fields, L.L.; Zheng, J.P.; Cheng, Y.; Xiong, P. RT low-power hydrogen sensor based on a single tin dioxide nanobelt. Appl. Phys. Lett. 2006, 88, 263102.

93. Lupan, O.; Chai, G.; Chow, L. Fabrication of $\mathrm{ZnO}$ nanorod-based hydrogen gas nanosensor. Microelectron. J. 2007, 38, 1211-1216.

94. Lupan, O.; Chai, G.; Chow, L. Novel hydrogen gas sensor based on single $\mathrm{ZnO}$ nanorod. Microelectron. Eng. 2008, 85, 2220-2225.

95. Lupan, O.; Emelchenko, G.A.; Ursaki, V.V.; Chai, G.; Redkin, A.N.; Gruzintsev, A.N.; Tiginyanu, I.M.; Chow, L.; Ono, L.K.; Roldan Cuenya, B.; Heinrich, H.; Yakimov, E.E. Synthesis and characterization of $\mathrm{ZnO}$ nanowires for nanosensor applications. Mater. Res. Bull. 2010, 45, 1026-1032.

96. Lupan, O.; Ursaki, V.V.; Chai, G.; Chow, L.; Emelchenko, G.A.; Tiginyanu, I.M.; Gruzintsev, A.N.; Redkin, A.N. Selective hydrogen gas nanosensor using individual ZnO nanowire with fast response at room temperature. Sens. Actuat. B 2010, 144, 56-66.

97. Huang, H.; Lee, Y.C.; Tan, O.K.; Zhou, W.; Peng, N.; Zhang, Q. High sensitivity $\mathrm{SnO}_{2}$ single-nanorod sensors for the detection of $\mathrm{H}_{2}$ gas at low temperature. Nanotechnology 2009, doi: 10.1088/0957-4484/20/11/115501.

98. Rout, C.S.; Kulkarni, G.U.; Rao, C.N.R. Room temperature hydrogen and hydrocarbon sensors based on single nanowires of metal oxides. J. Phys. D Appl. Phys. 2007, 40, 2777-2782.

99. Baik, J.M.; Kim, M.H.; Larson, C.; Yavuz, C.T.; Stucky, G.D.; Wodtke, A.M.; Moskovits, M. Pd-sensitized single vanadium oxide nanowires: Highly responsive hydrogen sensing based on the metal-insulator transition. Nano Lett.2009, 9, 3980-3984.

100. Wang, B.; Zhu, L.F.; Yang, Y.H.; Xu, N.S.; Yang, G.W. Fabrication of a $\mathrm{SnO}_{2}$ nanowire gas sensor and sensor performance for hydrogen. J. Phys. Chem. C 2008, 112, 6643-6647.

101. Ahn, M.-W.; Park, K.-S.; Heo, J.-H.; Park, J.-G.; Kim, D.-W.; Choi, K.J.; Lee, J.-H.; Hong, S.-H. Gas sensing properties of defect-controlled ZnO-nanowire gas sensor. Appl. Phys. Lett. 2008, 93, 263103:1-263103:3.

102. Choi, Y.J.; Hwang, I.S.; Park, J.G.; Choi, K.J.; Jae-Hwan, P.J.H.; Lee, J.H. Novel fabrication of an $\mathrm{SnO}_{2}$ nanowire gas sensor with high sensitivity. Nanotechnology 2008, doi: 10.1088/ 0957-4484/19/9/095508.

103. Ahn, M.W.; Park, K.S.; Heo, J.H.; Kim, D.W.; Choi, K.J.; Park, J.G. On-chip fabrication of ZnO-nanowire gas sensor with high gas sensitivity. Sens. Actuat. B 2009, 138, 168-173.

104. Duc Hoa, N.; Van Quy, N.; Anh Tuan, M.; Van Hieu, N. Facile synthesis of $p$-type semiconducting cupric oxide nanowires and their gas-sensing properties. Phys. E 2009, 42, 146-149.

105. Qurashi, A.; Yamazaki, T.; El-Maghraby, E.M.; Kikuta, T. Fabrication and gas sensing properties of $\mathrm{In}_{2} \mathrm{O}_{3}$ nanopushpins. Appl. Phys. Lett. 2009, 95, 153109:1-153109:3.

106. Qurashi, A.; Tabet, N.; Faiz, M.; Yamzaki, T. Ultra-fast microwave synthesis of ZnO nanowires and their dynamic response toward hydrogen gas. Nanoscale Res. Lett. 2009, 4, 948-954.

107. Qurashi, A.; Faiz, M.; Tabet, N.; Alam, M.W. Low temperature synthesis of hexagonal ZnO nanorods and their hydrogen sensing properties. Superlattice Microstruct. 2011, 50, 173-180. 
108. Qurashi, A.; El-Maghraby, E.M.; Yamazaki, T.; Shen, Y.; Kikuta, T. A generic approach for controlled synthesis of $\operatorname{In}_{2} \mathrm{O}_{3}$ nanostructures for gas sensing applications. J. Alloy. Compd. 2009, 481, L35-L39.

109. Qurashi, A.; El-Maghraby, E.M.; Yamazaki, T.; Kikuta, T. Catalyst supported growth of $\operatorname{In}_{2} \mathrm{O}_{3}$ nanostructures and their hydrogen gas sensing properties. Sens. Actuat. B 2010, 147, 48-54.

110. Khan, R.; Ra, H.W.; Kim, J.T.; Jang, W.S.; Sharma, D.; Im, Y.H. Nanojunction effects in multiple $\mathrm{ZnO}$ nanowire gas sensor. Sens. Actuat. B 2010, 150, 389-393.

111. Shen, Y.; Yamazaki, T.; Liu, Z.; Meng, D.; Kikuta, T. Hydrogen sensors made of undoped and Pt-doped $\mathrm{SnO}_{2}$ nanowires. J. Alloy. Compd. 2009, 488, L21-L25.

112. Xu, X.; Sun, J.; Zhang, H.; Wang, Z.; Dong, B.; Jiang, T.; Wang, W.; Li, Z.; Wang, C. Effects of $\mathrm{Al}$ doping on $\mathrm{SnO}_{2}$ nanofibers in hydrogen sensor. Sens. Actuat. B 2011, 160, 858-863.

113. Zhang, H.; Li, Z.; Liu, L.; Xu, X.; Wang, Z.; Wang, W.; Zheng, W.; Dong, B.; Wang, C. Enhancement of hydrogen monitoring properties based on $\mathrm{Pd}-\mathrm{SnO}_{2}$ composite nanofibers. Sens. Actuat. B 2010, 147, 111-115.

114. Liu, L.; Guo, C.; Li, S.; Wang, L.; Dong, Q.; Li, W. Improved $\mathrm{H}_{2}$ sensing properties of Co-doped $\mathrm{SnO}_{2}$ nanofibers. Sens. Actuat. B 2010, 150, 806-810.

115. Wang, Z.; Li, Z.; Sun, J.; Zhang, H.; Wang, W.; Zheng, W.; Wang, C. Improved hydrogen monitoring properties based on $\mathrm{p}-\mathrm{NiO} / \mathrm{n}-\mathrm{SnO}_{2}$ heterojunction composite nanofibers. J. Phys. Chem. C 2010, 114, 6100-6105.

116. Singh, N.; Ponzoni, A.; Gupta, R.K.; Lee, P.S.; Comini, E. Synthesis of $\operatorname{In}_{2} \mathrm{O}_{3}-\mathrm{ZnO}$ core-shell nanowires and their application in gas sensing. Sens. Actuat. B 2011, 160, 1346-1351.

117. Ahsanulhaq, Q.; Kim, J.H.; Lee, J.S.; Hahn, Y.B. Electrical and gas sensing properties of ZnO nanorod arrays directly grown on a four-probe electrode system. Electrochem. Commun. 2010, $12,475-478$.

118. Bie, L.-J.; Yan, X.-N.; Yin, J.; Duan, Y.-Q.; Yuan, Z.-H. Nanopillar ZnO gas sensor for hydrogen and ethanol. Sens. Actuat. B 2007, 126, 604-608.

119. Liu, Y.; Gao, C.; Pan, X.; An, X.; Xie, Y.; Zhou, M.; Song, J.; Zhang, H.; Liu, Z.; Zhao, Q. Synthesis and $\mathrm{H}_{2}$ sensing properties of aligned $\mathrm{ZnO}$ nanotubes. Appl. Surf. Sci. 2011, 257, 2264-2268.

120. Zhu, L.F.; She, J.C.; Luo, J.Y.; Deng, S.Z.; Chen, J.; Ji, X.W.; Xu, N.S. Self-heated hydrogen gas sensors based on Pt-coated $\mathrm{W}_{18} \mathrm{O}_{49}$ nanowire networks with high sensitivity, good selectivity and low power consumption. Sens. Actuat. B 2011, 153, 354-360.

121. Tonezzer, M.; Lacerda, R.G. Zinc oxide nanowires on carbon microfiber as flexible gas sensor. Phys. E 2010, doi: 10.1016/j.physe.2010.11.029.

122. Lim, Z.H.; Chia, Z.X.; Kevin, M.; Wong, A.S.W.; Ho, G.W. A facile approach towards ZnO nanorods conductive textile for room temperature multifunctional sensors. Sens. Actuat. B 2010, $151,121-126$.

123. Patil, L.A.; Shinde, M.D.; Bari, A.R.; Deo, V.V. Highly sensitive and quickly responding ultrasonically sprayed nanostructured $\mathrm{SnO}_{2}$ thin films for hydrogen gas sensing. Sens. Actuat. B 2009, 143, 270-277.

124. Al-Hardan, N.; Abdullah, M.J.; Aziz, A.A. The gas response enhancement from $\mathrm{ZnO}$ film for $\mathrm{H}_{2}$ gas detection. Appl. Surf. Sci. 2009, 255, 7794-7797. 
125. Zhang, C.; Boudiba, A.; Navio, C.; Bittencourt, C.; Olivier, M.-G.; Snyders, R.; Debliquy, M. Highly sensitive hydrogen sensors based on co-sputtered platinum-activated tungsten oxide films. Int. J. Hydrog. Energy 2011, 36, 1107-1114.

126. Stamataki, M.; Tsamakis, D.; Brilis, N.; Fasaki, I.; Giannoudakos, A.; Kompitsas, M. Hydrogen gas sensors based on PLD grown NiO thin film structures. Phys. Status Solidi A 2008, 205, 2064-2068.

127. Huh, J.; Park, J.; Kim, G.T.; Park, J.Y. Highly sensitive hydrogen detection of catalyst-free $\mathrm{ZnO}$ nanorod networks suspended by lithography-assisted growth. Nanotechnology 2011, doi: 10.1088/0957-4484/22/8/085502.

(C) 2012 by the authors; licensee MDPI, Basel, Switzerland. This article is an open access article distributed under the terms and conditions of the Creative Commons Attribution license (http://creativecommons.org/licenses/by/3.0/). 